\title{
División dialectal del español de América según sus hablantes Análisis dialectológico perceptual
}

\author{
Miguel Ángel Quesada Pacheco* \\ Universitetet i Bergen, Noruega
}

\begin{abstract}
Resumen
El presente estudio traza una división dialectal del español de América según la opinión de sus hablantes, mediante un acercamiento en el campo de la dialectología perceptual. Se recogieron datos a través de una encuesta que evalúa similitudes y diferencias acerca de la forma de hablar de los entrevistados con las de otros países. De este modo, se examinan y entrecruzan las opiniones que tienen los hispanoamericanos de sus propias formas de hablar la lengua española. Además, se cartografían los resultados en forma de mapas sintéticos que muestren la división dialectal de Hispanoamérica según la percepción de los entrevistados (conocidos como mapas perceptuales, mentales o virtuales). Finalmente, se comparan los resultados recopilados entre los países entrevistados.
\end{abstract}

Palabras clave: dialectología perceptual, actitudes lingüísticas, sociolingüística, geolingüística, lengua española.

*Para correspondencia, dirigirse a: Miguel Ángel Quesada Pacheco (miguel.quesada@, if.uib.no), Universitetet i Bergen, Department of Foreign Languages, Postboks 7805, 5020 Bergen, Noruega. 


\title{
Dialectal division of American Spanish according to its Speakers. An analysis from Perceptual Dialectology
}

\begin{abstract}
The present article shows a dialectal division of American Spanish according to the opinion of its speakers, within a Perceptual Dialectology approach. Data was gathered through a series of interviews where speakers mentioned linguistic similitudes and differences between them and speakers of other countries. These speakers' perceptions and opinions were evaluated and cross-linked. Besides, their opinions were represented in perceptual or mental maps. Finally, the results were compared within the different countries in the survey.
\end{abstract}

Keywords: perceptual dialectology, linguistic attitudes, sociolinguistics, geolinguistics, Spanish language.

Recibido: $12 / 08 / 14 \quad$ Aceptado: $13 / 10 / 14$

\section{INTRODUCCIÓN}

En Hispanoamérica, los estudios dialectales tienen una larga tradición que se remonta a inicios del siglo XX, y los estudios de este tipo han ido en dos vertientes, las cuales son la dialectología en sí y la geografía lingüística (cfr. Quesada Pacheco 2010: 179-197). Pero las investigaciones dentro de la llamada dialectología perceptual, donde se toma la opinión de los hablantes acerca de su forma de hablar y se representa en mapas, está apenas en sus inicios.

De hecho, en el mundo hispánico, el interés por la dialectología perceptual se observa a partir del presente siglo en los estudios de Alfaraz (2002) sobre Cuba, de Serrano (2002) sobre México, de Moreno Fernández y Moreno Fernández (2002) sobre España, el de Puerto Rico y México (Boomershine 2006), el de Venezuela en comparación con España (Díaz-Campos y NavarroGalisteo 2009) y el último, de Quesada Pacheco (2013), sobre Costa Rica.

En este sentido, el presente estudio intenta, como objetivo principal, trazar una división dialectal del español de América según la opinión de los hablantes. Para lograr lo anterior, se pretende llevar a cabo tres objetivos 
secundarios. En primer lugar, realizar un estudio piloto; es decir, un acercamiento inicial de carácter más que todo experimental y de conjunto, en el campo de la dialectología perceptual en toda Hispanoamérica, tomando como meta recopilar datos en los 19 países que tienen el español como lengua oficial, mediante una encuesta acerca de las similitudes y diferencias que los entrevistados encuentran entre su forma nacional de hablar y la del resto del continente. En segundo lugar, examinar, a raíz de encuestas en el terreno, las percepciones que tienen los hispanoamericanos acerca de sus propias formas de hablar la lengua española. Como meta de este objetivo está cartografiar los resultados en forma de mapas sintéticos que muestren la división dialectal de Hispanoamérica según la percepción de los entrevistados (conocidos como mapas perceptuales, mentales o virtuales). Por último, se pretende comparar los resultados recopilados entre los países, cuya meta es trazar un mapa general de la manera como todos los informantes perciben y evalúan las diferentes maneras de hablar en el Nuevo Mundo.

Las preguntas directrices que acompañan los objetivos anteriores son las siguientes:

1. ¿Son los entrevistados capaces de percibir diferencias dialectales?

2. ¿A qué países o regiones de la América hispana asocian los entrevistados su manera de hablar?

3. ¿Confirman o refutan las respuestas de los entrevistados los resultados de los estudios dialectológicos y geolingüísticos realizados en Hispanoamérica?; o bien, ¿se observa alguna conexión entre las opiniones de los informantes y las propuestas de división dialectal hechas por los que se han encargado de estudiar la producción lingüística en el espacio físico-geográfico del continente americano?

El presente estudio representa un esfuerzo por extender esta disciplina a todo el mundo hispanohablante en general, y al hispanoamericano en particular, haciendo un trabajo de conjunto, global. Aun así, no pretende ser exhaustivo; al contrario, se trata más que nada de un estudio inicial, que dé bases para futuras investigaciones de más contenido y arroje más luces acerca de la concepción que tienen los hispanoamericanos de su forma de hablar, tanto dentro de su país como de los países vecinos. 


\section{NOCIONES TEÓRICAS}

De acuerdo con Moreno Fernández,

[1]os hablantes suelen tener una clara conciencia del prestigio de su variedad y de su lejanía, en el uso lingüístico y en la interpretación de la variación sociolingüística, respecto de otras variedades. [...] Los individuos, al hablar entre sí, son capaces de distinguir a los que pertenecen a su misma comunidad de los que son ajenos a ella (1993: 15).

Siendo así la situación, el lingüista estará en condiciones de estudiar y de medir, en distintas maneras, hasta dónde llega la conciencia de los hablantes respecto de su forma de hablar y de la de los que lo rodean. Para llegar a esa meta, el lingüista se vale de la disciplina llamada dialectología perceptual o perceptiva, la cual, según Anders, Hundt y Lasch (2010: XI-XIII) ${ }^{1}$, se ocupa de responder principalmente las siguientes interrogantes:

1. ¿Cómo imaginan los no lingüistas el mapa dialectal de su nación o de su región? A esta pregunta se responde con la cartografía mental o perceptual; es decir, con el trazado de mapas (o gráficos) lingüísticos que condensen en el espacio las respuestas obtenidas.

2. ¿Qué rasgos dialectales destacan los no lingüistas? Esta interrogante tiene como fin agrupar los rasgos dialectales que enumera la gente como sobresalientes e importantes en la distinción de sus dialectos.

3. ¿Con qué rasgos dialectales asocian los no lingüistas los dialectos en cuestión? Esta pregunta se encarga de la confección de rasgos dialectales por asociación.

Para Anders, Hundt y Lasch (2010: XII), la pregunta c) es relevante porque permite reconstruir una parte de la sabiduría cotidiana del entrevistado; además, queda clara la manera cómo interactúan los rasgos dialectales evidentes (reales) con los rasgos asociados. En otras palabras, se establece una relación entre la realidad (los rasgos factuales del dialecto en cuestión) y la percepción; de modo que hay una relación de concordancia cuando se asocian ciertos rasgos que el dialecto de hecho tiene. Por el contrario, se

\footnotetext{
1 Es importante acotar que los mencionados autores se refieren más que todo al mundo dialectal alemán.
} 
da una relación de divergencia cuando se asocian rasgos que el dialecto en cuestión no posee.

De acuerdo con Iannàccaro y Dell'Aquila, la dialectología perceptual está en estrecha relación con la geografía y estudia el lenguaje desde adentro, "from the standpoint of the members of the communities living there" (2001: 265); es decir, desde la perspectiva del hablante mismo, oponiendo este concepto al estudio del lenguaje desde afuera; o sea, desde el ángulo de una persona experta, sea dialectólogo o lingüista en general.

En este sentido, la dialectología perceptual no solo es una disciplina híbrida, a caballo entre dos formas de ver el lenguaje, como son la sociolingüística y la dialectología, sino que también adopta un papel interactivo, en vista de que evalúa de manera científica la opinión de los hablantes, toma su parecer y opiniones (Iannàcaro y Dell'Aquila 2001: 266). Además, dentro de esta disciplina híbrida, no se trata del análisis de la variación interna de la lengua o de los fenómenos concernientes al idioma, sino que se centra en hábitos lingüísticos y nociones acerca de la identificación lingüística (Iannàcaro y Dell'Aquila 2001, ubi supra).

Contrario a lo que se puede imaginar, la opinión de los hablantes puede jugar un papel decisivo o muy importante en la confección de zonas dialectales y sus límites. Si bien el lingüista cuenta con los mecanismos y métodos para delimitar dichas zonas y sus fronteras, el hablante tiene la ventaja de que ve el fenómeno desde su experiencia personal o comunitaria. Siguiendo de cerca a Iannàccaro y Dell'Aquila (2001: 266-269), algunas oposiciones en la manera de apreciar el dialecto o las fronteras dialectales entre los lingüistas y los hablantes se ofrecen en los siguientes axiomas:

1. El lingüista propone o impone una división dialectal desde afuera. El hablante reconoce sus propias fronteras desde la experiencia cotidiana, en contacto con los demás de su comunidad hablante.

2. El lingüista construye isoglosas "éticas"; es decir, objetivamente vistas y lejanas a la comunidad hablante ${ }^{2}$. El hablante construye isoglosas "émicas"; es decir, desde sus propios espacios ${ }^{3}$.

\footnotetext{
2 "By etic we mean that kind of knowledge and analysis made by an observer who is alien to the culture and uses concepts and ways of analysis which are external to the culture itself" (Iannàcaro y Dell'Aquila 2001: 276, nota 5).

"Emic, on the other hand, is not only the way of acquiring knowledge typical of the members who are internal to any culture, but also of whichever type of approach that tires to account for the vision of ther world peculiar to a certain community" (Iannàcaro y Dell'Aquila 2001: 276, nota 5).
} 
3. El lingüista teoriza, debate y discute, pone en duda y en crisis las fronteras dialectales. El hablante las ve como un hecho y no le perturban, ni siquiera las pone en duda. En este sentido, Bucholtz et al. tienen razón al afirmar que "the distinction between languages, dialects, and styles, widely recognized as problematic by sociolinguists, is generally not carefully maintained by nonlinguists" (2007: 348).

4. El lingüista aplica métodos y técnicas. Por su parte, el hablante aplica su propia experiencia.

5. El lingüista construye fronteras dialectales. El hablante percibe las fronteras dialectales.

6. El lingüista se basa en determinados hechos lingüísticos recogidos in situ, mientras que el hablante se basa en generalizaciones o estereotipos.

7. El lingüista plasma divisiones dialectales estáticas, pero el hablante interioriza divisiones dialectales dinámicas.

8. El lingüista toma en cuenta conceptos externos acerca de las fronteras dialectales. El hablante toma en cuenta la estructura interna de la comunidad hablante.

9. El lingüista justifica las divisiones dialectales en hechos lingüísticos concretos (fonética, gramática, léxico), pero el hablante traza las divisiones dialectales, por lo general en hechos no lingüísticos, y muchas veces influidos por factores ideológicos o sociales.

10. El lingüista distingue una zona dialectal 1 de una 2 , y hasta divisiones internas de cada zona dialectal. Por el contrario, el hablante distingue "los que hablan como yo" de "los que hablan distinto a mí", con lo cual deja de lado posibles divisiones internas.

11. El lingüista se concentra en la producción lingüística en términos fonéticos, gramaticales, etc., mientras que el hablante se concentra en la producción pragmática y en el valor comunicativo de la lengua.

12. El lingüista llega a elevados niveles de racionalización y se deja influir por los asuntos de lengua. El hablante, por su parte, no alcanza elevados niveles de racionalización y se deja influir poco por los asuntos propios de la lengua.

13. El lingüista traza fronteras dialectales con detalle. En el hablante, sus fronteras dialectales están trazadas en términos generales y a veces borrosos.

Estas diferencias se tienen que dar, ya que, como apunta Moreno Fernández (2009: 32), "la interpretación que los hablantes hacen de las formas y 
manifestaciones de su lengua no tiene por qué coincidir con la perspectiva de los estudiosos del lenguaje". Pero esta relación diferencial es importante, ya que, como agrega el mencionado investigador, se da la circunstancia de que el juicio de los lingüistas y los profesores no puede prescindir, sin más, de la opinión de los hablantes ni de la percepción que estos tienen de las variedades de su propia lengua, entre otras razones porque la existencia de estas variedades, como tales, depende en gran medida del modo en que las percibe la comunidad lingüística.

Por otra parte, y según Iannàcaro y Dell'Aquila (2001: 268), las fronteras dialectales propuestas por los lingüistas no siempre calzan con las fronteras dialectales propuestas por los hablantes. Sin embargo, habrá que ver esto con cautela, ya que el estudio de dialectología perceptual recientemente hecho en Costa Rica demuestra que los hablantes, sean cuales sean las razones que tengan para justificar la división dialectal de su entorno, tienen una conciencia muy clara y profunda de las fronteras dialectales, y muchas veces pueden llegar a acercarse y hasta a competir con las propuestas por los estudiosos de la lengua (Quesada Pacheco 2013). Es más, las opiniones de los hablantes pueden tener mucho peso en la propuesta o rechazo de determinadas zonas dialectales sugeridas por los lingüistas.

En líneas generales, el fin primordial de la dialectología perceptual es tratar la cartografía geolingüística desde la percepción del hablante, o desde su conciencia lingüística; no desde su producción, ni de las inferencias a que llega el investigador mediante la recolección de datos. Esta disciplina se fundamenta en lo que el hablante siente, opina, cree, de su propia forma de hablar, o de la forma de hablar de los demás, y emplea como métodos de análisis los que caracterizan a la geografía lingüística, entre otros (cfr. Stewart 2011:3). En este sentido, se establece una relación entre la identidad lingüística del hablante y su espacio geográfico, y el producto final son por lo general mapas virtuales o mentales.

Cuando se habla de mapas mentales, significa que se establece una oposición entre lo real y lo virtual; el espacio deja de ser concreto, material, sea referido a una ciudad, a un pueblo o a cualquier espacio geofísico, para pasar al espacio simbólico, tal como lo define Caravedo:

De modo específico, en el terreno de las lenguas los hablantes elaboran -sobre la base de creencias transmitidas de generación en generación a las que se añaden las de la propia experiencia vital- ideas, no siempre justificadas ni razonadas sobre el espacio ajeno, en relación con las cuales, reconocen y evalúan modalidades o dialectos diversos de los propios. Gran parte de las valoraciones lingüísticas se basan en esas conceptualizaciones que son, en verdad, solo creencias o suposiciones que no necesariamente tienen correspondencia exacta con una realidad 
fáctica, de tal modo que pueden llegar a ser falsas, imprecisas o arbitrarias (2012: 7-8).

Caravedo (2012: 9) se refiere a tres órdenes en la concepción del espacio de una ciudad:

a) El orden material, que tiene que ver con determinadas características físicas y ubicables concretamente;

b) el orden social: en las ciudades hay contenido humano, hay redes sociales, intercomunicación entre sus habitantes;

c) el orden mental: las ciudades son lo que la gente piensa de ellas, son una construcción simbólica, de significados, a través de los cuales se determinan los valores, todos subjetivos.

En mi opinión, estos órdenes perfectamente se pueden asociar a cualquier espacio del ser humano, no necesariamente al urbano. En consecuencia, valen también para aplicarlos al presente estudio, el cual no se refiere al espacio urbano en sí, sino a un espacio general, determinado por fronteras políticas.

En resumen, y visto en líneas generales, el estudio empírico del lenguaje se puede realizar fundamentalmente desde dos ángulos, según el tipo de fuentes de datos: a) el emanado de una investigación que toma en cuenta la producción del entrevistado, y cuyos datos se pueden analizar empleando distintos métodos (sociolingüística, dialectología, pragmalingüística, etc.), y b) el que fundamenta su estudio sobre la base de las opiniones de lo que dice la gente acerca de su lengua o dialecto (cfr. Preston 1999: xxiii-xxiv; Jara 2010: 19-24). A su vez, este puede estudiarse desde tres ámbitos disciplinarios autónomos: a) las actitudes lingüísticas, b) la lingüística popular, y c) la dialectología perceptual.

\section{CONSIDERACIONES METODOLÓGICAS}

Tal como se ha estado aplicando la dialectología perceptual en el mundo hispanohablante, son distintas las maneras como se ha abordado el problema, tal como se verá en las siguientes líneas.

En primer lugar, uno de los fines de la dialectología perceptual es representar los datos recopilados en forma de mapas perceptuales, llamados también mapas mentales. Se les llama mentales porque se basan en la imaginación del hablante, no en las inferencias que pudiera hacer el lingüista o dialectólogo al recoger los datos sobre la producción lingüística de los 
hablantes. Sin embargo, en los estudios de este tipo no siempre se sigue esta premisa y, por lo tanto, no se representan los datos recopilados en forma de mapas perceptuales o mentales. Por ejemplo, de los trabajos conocidos hasta la fecha en el ámbito de la lengua española, únicamente dos (Serrano 2002 y Quesada Pacheco 2013) se encargan de hacer mapas; el resto de los autores consultados (Alfaraz 2002; Moreno Fernández y Moreno Fernández 2002; Boomershine 2006; Díaz-Campos y Navarro-Galisteo 2009) presentan los resultados en forma de cuadros o figuras, y con sus respectivos porcentajes.

Algunos de los autores han empleado mapas vacíos, de modo que los entrevistados los rellenan con trazos que pueden encerrar zonas o subzonas dialectales. Así fue como se trabajó con informantes procedentes de Madrid en el reconocimiento de variantes dialectales de España, tales como el canario, el andaluz, el castellano central y el castellano septentrional (cfr. Moreno Fernández y Moreno Fernández 2002).

También se han aplicado encuestas con escalas, de manera que a los entrevistados se les pregunta, de un número $\mathrm{X}$ a un número $\mathrm{Y}$ (por ejemplo, de 1 a 5), sobre la gradación en la similitud o diferencia de su propia forma de hablar con el habla de otras regiones de su país. Este método fue aplicado por Moreno Fernández y Moreno Fernández (ubi supra) entre los informantes madrileños.

Respecto de las variables sociales de los entrevistados, es importante recalcar que, en todos los trabajos de dialectología perceptual sobre algún aspecto del español, los autores consultados no solo se han esmerado en adjuntar datos geolingüísticos, sino también sociolingüísticos, tales como sexo, edad, instrucción formal, además de su procedencia. Lo anterior, se podría afirmar, es una novedad respecto de los trabajos clásicos de esta índole (por ejemplo, en Sibata [1999] para el Japón y Weijnen [1999] en Holanda), donde por lo general se tomaba únicamente el origen del encuestado.

En cuanto a la extensión geofísica del objeto de estudio, hay investigaciones (por ejemplo, Moreno y Moreno, Serrano y Quesada Pacheco, antes mencionados), donde se encuestaron únicamente personas del mismo país -España, México y Costa Rica, respectivamente- con el fin de obtener datos solamente de ese país y para ese país; es decir, a estas personas se les ha entrevistado para opinar sobre algún aspecto del español de su país en particular. Otros trabajos se caracterizan por entrevistar personas de distintos países hispanohablantes, sea del continente americano, sea en combinación con España (Alfaraz 2002; Boomershine 2006; Díaz-Campos y NavarroGalisteo 2009). En estos, se tomaron en cuenta aspectos del español de dos o más países, de modo que los entrevistados podían dar su parecer no solo en cuanto a su país de origen, sino también de los demás de la encuesta. 
Por último, y en lo concerniente a aspectos lingüísticos por estudiar, hay trabajos que se concentran en datos específicos de algún nivel de la lengua, tal como sucede con el trabajo sobre la opinión de los hablantes mexicanos y puertorriqueños en relación con los fonemas nasal dental $/ \mathrm{n} /$, percusivo /r/ y fricativo alveolar/s/ en posición final (Boomershine 2006). Otros se concentran en proponer preguntas abiertas, como sucede en el trabajo de Quesada Pacheco (2013) con los entrevistados de Costa Rica.

En suma, si bien los trabajos que tocan el español, en general, son bien escasos, estos presentan novedades, tanto en la estructura como en la metodología, que no se habían tocado en la dialectología perceptual de otras zonas lingüísticas, incluso en el mundo anglohablante, donde en los últimos años esta disciplina ha adquirido mucha fuerza.

En lo relativo al presente estudio, los datos se recogieron entre 2008 y 2010, en cada una de las capitales de Hispanoamérica donde el español es lengua oficial, como parte de una investigación más global en el campo de las actitudes lingüísticas. Se trata del proyecto Actitudes lingüisticas e Identidad en Hispanoamérica y España, patrocinado por el Consejo Noruego de Investigaciones y la Universidad de Bergen, donde se aplicaron 400 encuestas en cada ciudad capital hispanohablante, lo cual da para Hispanoamérica un total de 7.600 entrevistas, con el fin de estudiar más que nada aspectos cognitivos, afectivos y actitudinales o pragmáticos entre hispanohablantes, además de asuntos que tienen que ver con corrección idiomática.

Desde la perspectiva diatópica, el cuestionario se dividió básicamente en dos ámbitos: preguntas que recogen opiniones concernientes al habla del país donde se aplicó la encuesta, y preguntas con opiniones sobre los demás países hispanohablantes. Así, dentro de este cuestionario, que constaba de 30 preguntas, se hicieron dos de carácter geográfico-perceptual en la sección llamada "Percepciones cognitivo-lingüísticas", y se preguntó a las personas consultadas lo siguiente:

Pregunta 29: Diga/mencione tres países donde hablan el español/castellano igual o parecido a como usted lo habla.

Pregunta 30: Diga/mencione tres países donde hablan el español/castellano diferente a como usted lo habla.

En la presente investigación solamente se estudiará la primera pregunta. Se pintará un mapa donde se resaltarán los países que la generalidad de los informantes caracterizó como los más parecidos, incluyendo el país de partida de la encuesta, tomando como axioma el hecho de que si no mencionaron otros países era porque los entrevistados los sentían lejanos o distintos a su propia forma de hablar. 
Para las ilustraciones, se bajó del Internet un mapa mudo, sin colorear ${ }^{4}$, de la América hispana y se rediseñó coloreando cada uno de los países, los cuales sirvieron de base para la ilustración de las zonas dialectales en cuestión.

El análisis por países va de norte a sur y de este a oeste, en el siguiente orden: México, Cuba, República Dominicana, Puerto Rico, Guatemala, El Salvador, Honduras, Nicaragua, Costa Rica, Panamá, Colombia, Venezuela, Ecuador, Perú, Bolivia, Paraguay, Chile, Argentina y Uruguay.

Por el momento, y en términos generales, se dejarán de lado las variables de sexo, edad, instrucción y procedencia urbana de los entrevistados, para poder aplicarlas en un estudio ulterior.

\section{ANÁLISIS DE DATOS POR PAÍSES}

\subsection{MÉXICO}

Según se observa en los datos suministrados por Morett (2014: 894-895), los países que los entrevistados mexicanos sienten como más próximos por su manera de hablar son Guatemala, Honduras y El Salvador (mapa 1).

4 Disponible en: http://profpriscilalemos.blogspot.no/2012/05/mapa-mudo-americalatina-politico-8-ano.html. 


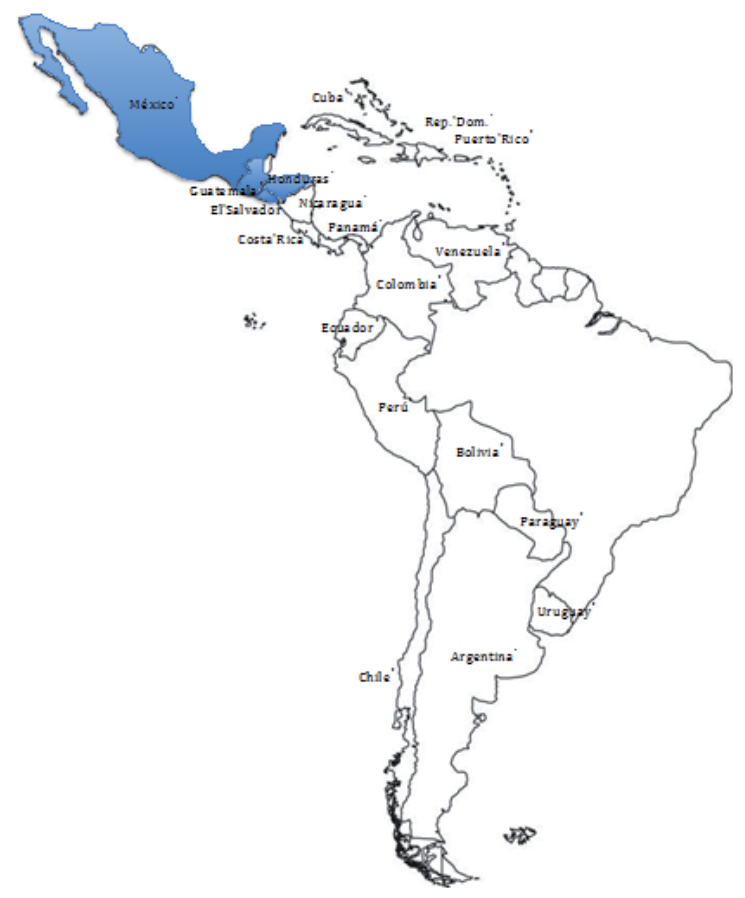

Mapa 1. Países de habla similar, según los mexicanos

Interesante es notar que, después de los países mencionados, España tuvo un lugar significativo en las menciones como país de habla similar. Según lo explica Morett (2014),

[e]n lo que respecta a España, se ubicó en segunda posición dentro de los países elegidos como primera respuesta (con casi un 50\% menos de preferencias en relación con Guatemala). La explicación podría estar relacionada con el hecho de que el dialecto mexicano, a decir de Lope Blanch (1999), es más apegado que el de España a la lengua histórica, y muchos entrevistados identificaron el español hablado en la península ibérica más con la lengua histórica que con los usos lingüísticos del siglo XXI. Tal vez influya también el que para muchos la variante europea se considere la norma a seguir, y la percepción de similitud obedezca más a una aspiración que a observaciones concretas. 


\subsection{CUBA}

Los datos que Sobrino et al. (2014: 367-371) destacan sobre la opinión de los habaneros, coinciden en ver a Venezuela, Puerto Rico y la República Dominicana como países con habla similar a los cubanos (mapa 2).

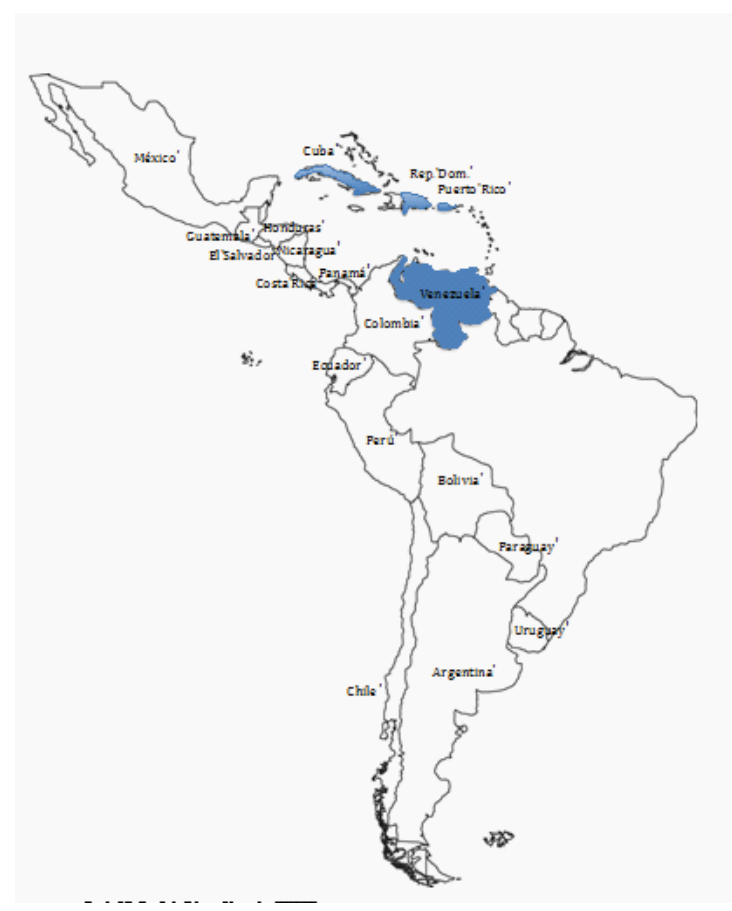

Mapa 2. Países de habla similar, según los cubanos

De acuerdo con las autoras (ubi supra),

[m]uy interesante es el hecho de que, con excepción de España, los países que registran un mayor porcentaje integran lo que se considera el "Caribe hispánico", según estudios dialectológicos realizados. 


\subsection{RepÚBlica Dominicana}

Siguiendo la investigación de Severino (2014), las personas entrevistadas en Santo Domingo, la capital dominicana, consideran que las personas del Caribe insular hablan de manera parecida, además de que señalaron a Venezuela como de habla similar (mapa 3).

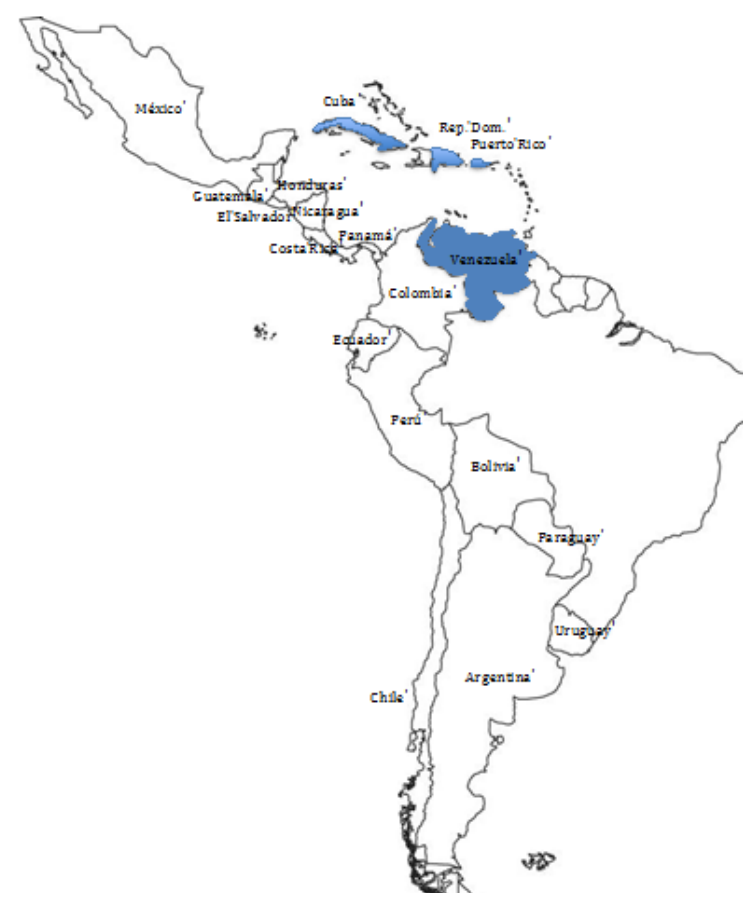

Mapa 3. Países de habla similar, según los dominicanos

Severino (op. cit.) aduce que "estas naciones comparten entre sí muchas tradiciones religiosas, culturales, sociales y dialectales, lo cual favorece la valoración positiva que se tiene de ellos".

\subsection{Puerto Rico}

La investigación de Mojica de León (2014) sobre las opiniones de los habitantes de San Juan, capital de Puerto Rico, muestran que los entrevistados sienten que su habla se parece a la de los cubanos, los dominicanos, los venezolanos y los panameños (mapa 4). 


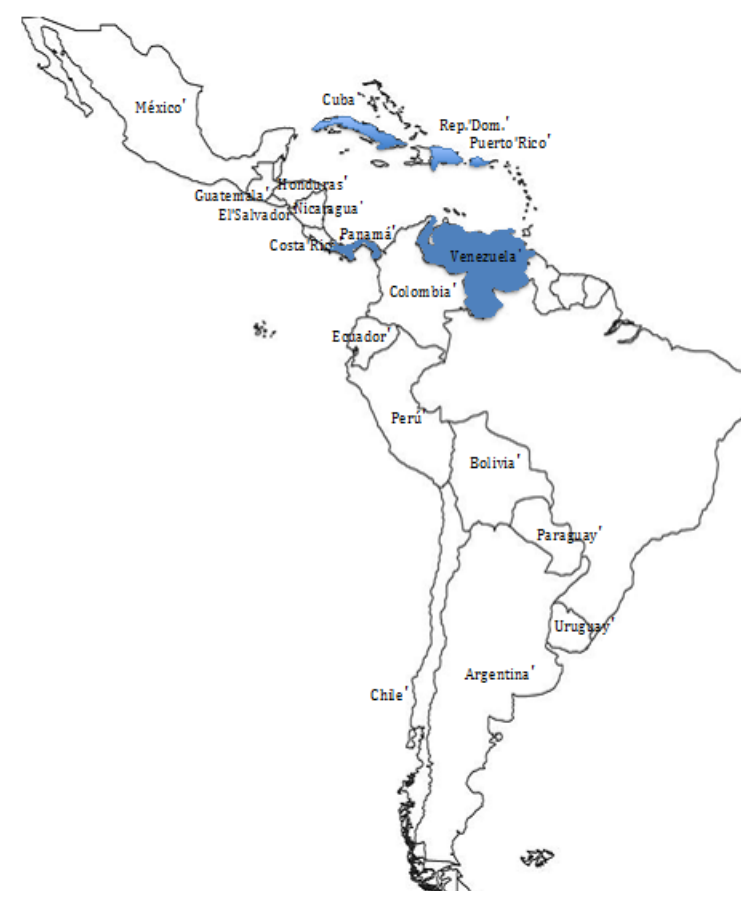

Mapa 4. Países de habla similar, según los puertorriqueños

De acuerdo con Mojica de León (2014),

[d]e los datos obtenidos puede desprenderse que la variante "cubana" es la que más se asocia con la variante puertorriqueña, seguida de la dominicana, la venezolana y la panameña, lo que evidencia una conciencia lingüística de los informantes y el reconocimiento de una zona dialectal; es decir, la unificación de la cuenca caribeña.

\subsection{Guatemala}

Los datos recopilados en la investigación sobre la ciudad de Guatemala (Acevedo y Quesada Pacheco 2014: 653) muestran que los capitalinos chapines se sienten cercanos al habla de los mexicanos, de los salvadoreños y de los costarricenses (mapa 5). 


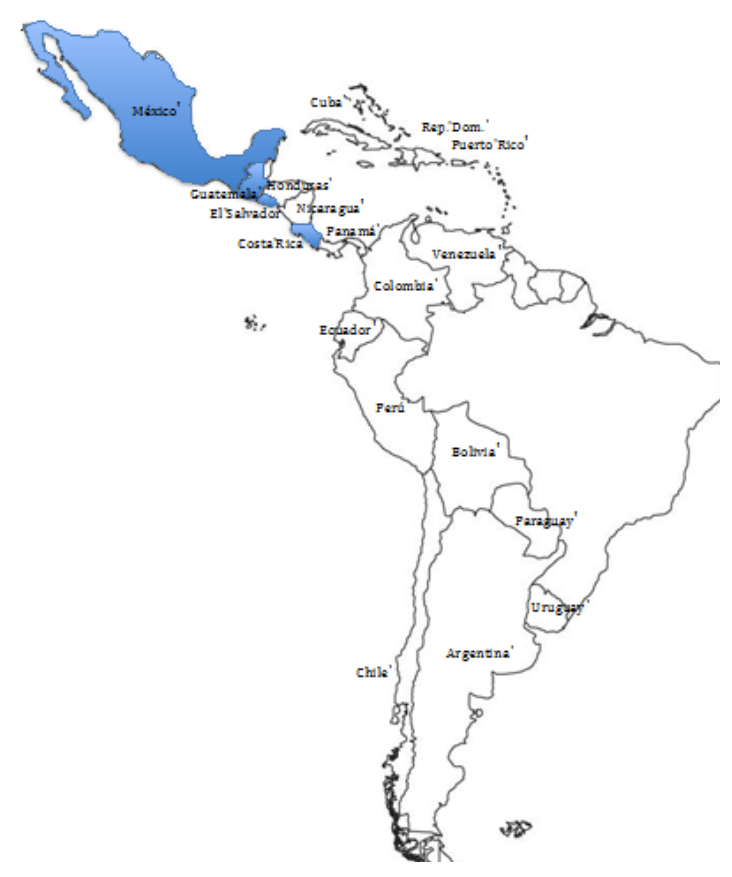

Mapa 5. Países de habla similar, según guatemaltecos

Según lo explican los investigadores mencionados (ubi supra), "[s]iendo estos tres países cercanos a Guatemala, es muy probable que esto refleje el contacto estrecho que puedan tener los guatemaltecos con los países vecinos".

\subsection{El SALVAdor}

En lo concerniente a San Salvador, la capital de El Salvador, los entrevistados por Rivera (2014) se reflejan en el habla de los guatemaltecos, los hondureños y los nicaragüenses (mapa 6). 


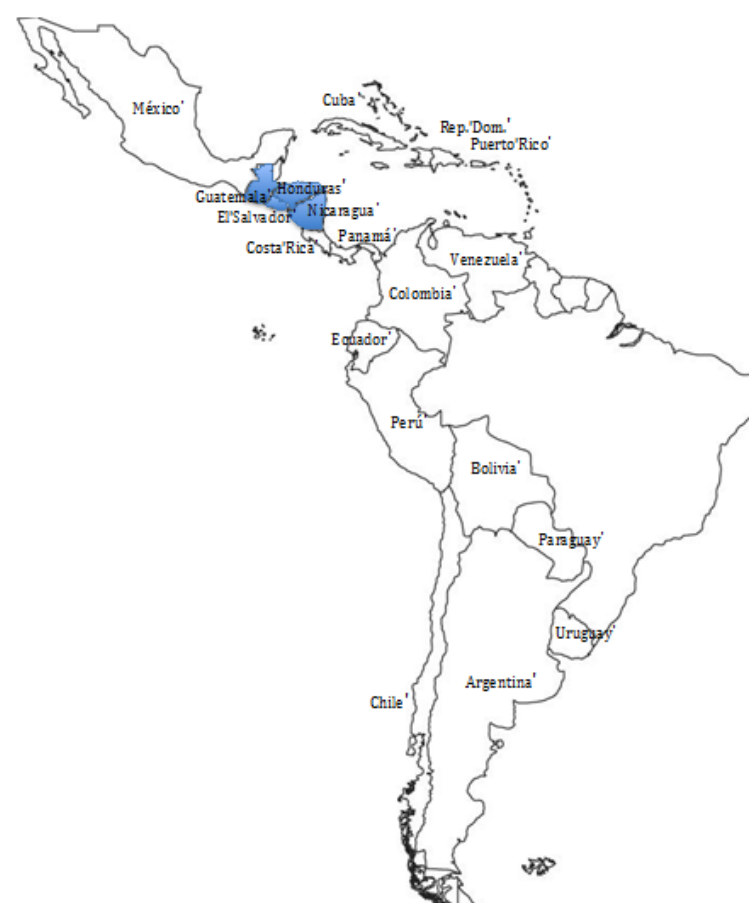

Mapa 6. Países de habla similar, según salvadoreños

Rivera (2014: 524) atribuye esta semejanza a lazos prehispánicos:

Ya antes se dijo que, junto con Honduras, en El Salvador hubo una fuerte presencia de la cultura y la lengua lencas, que formaban un tronco común que se dividió hace cerca de 24 siglos. En el caso de Nicaragua, nación con la que también hay vínculos lingüísticos prehispánicos, es notoria su presencia como segunda y tercera opción. Canfield (1960: 85), explica que hay una unidad fonética entre el español de Honduras, El Salvador y Nicaragua; una unidad que parece haber sobrevivido con el tiempo, y esta investigación hace notoria la conciencia que los habitantes de San Salvador tienen de ello; por lo menos de la presencia de rasgos de semejanza entre esos tres países. 


\subsection{Honduras}

De acuerdo con Hernández (2014: 767-768), los hondureños asocian su forma de hablar a la de los salvadoreños en primer lugar; luego a la de los costarricenses y, en última instancia, a la de los guatemaltecos y a los nicaragüenses (mapa 7).

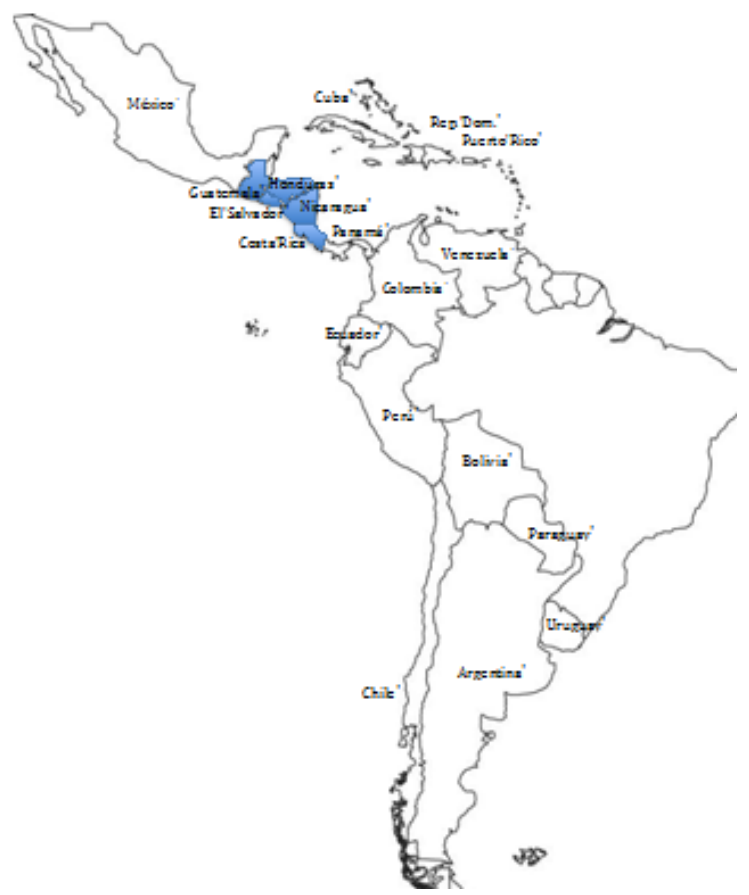

Mapa 7. Países de habla similar, según hondureños

Según Hernández (2014: 769),

[e]ste estudio nos permite conocer que la actitud hacia territorios vecinos, especialmente hacia el centroamericano, es muy positiva. Refleja una identidad global con respecto al español hablado en estas zonas. Si bien es cierto que no hay una uniformidad total, ciertamente el hecho de compartir rasgos léxicos, fonéticos y morfosintácticos ha hecho que los hondureños se identifiquen con los países vecinos, reconociendo la identidad lingüística que nos rodea. 


\subsection{NiCARAGUA}

Los informantes entrevistados en Managua, la capital nicaragüense, opinaron, según los datos recopilados por Zamora (2014: 985-987), que su habla se parece a la de Honduras, Guatemala, El Salvador y Costa Rica (mapa 8).

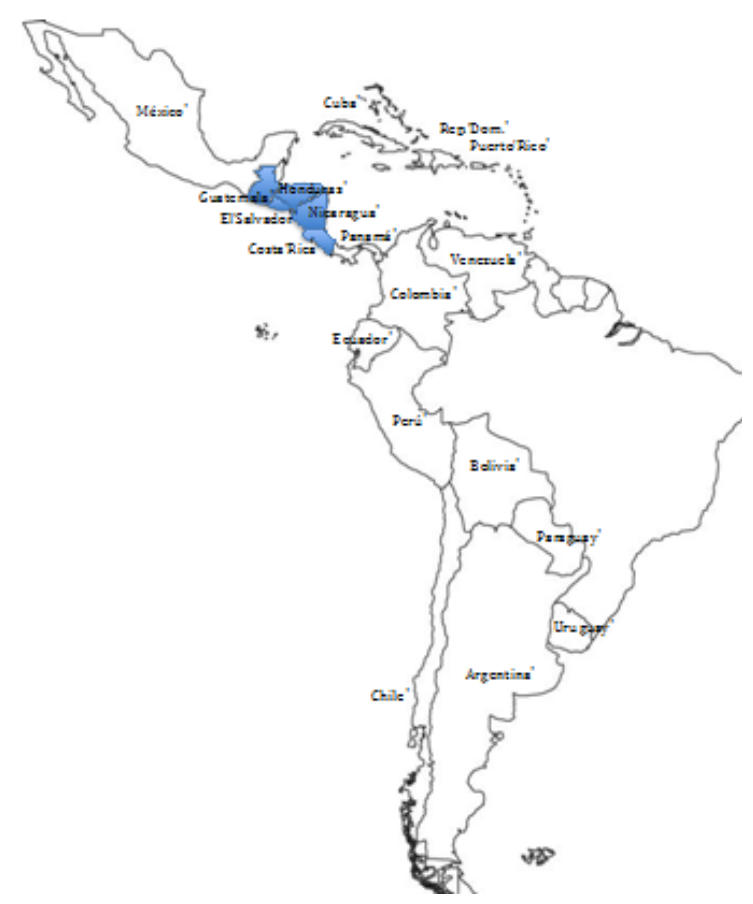

Mapa 8. Países de habla similar, según los nicaragüenses

Lo anterior continúa con la tendencia ya vista en los países anteriores, según la cual los centroamericanos perciben su habla como similar, frente a las hablas del resto de América. Tal como lo dice la autora, "con esta investigación se demuestra que la población en estudio asemeja el español de Nicaragua al de los países centroamericanos (Honduras, El Salvador, Guatemala y Costa Rica), lo cual puede responder a la cercanía existente con estos" (Zamora 2014: 987). 


\subsection{Costa Rica}

Las conclusiones a las que llegan Calvo y Castillo (2014: 270-271) con las entrevistas llevadas a cabo en San José de Costa Rica son que los informantes capitalinos consideran que el habla costarricense guarda similitudes con las hablas de Colombia, Panamá y El Salvador (mapa 9).

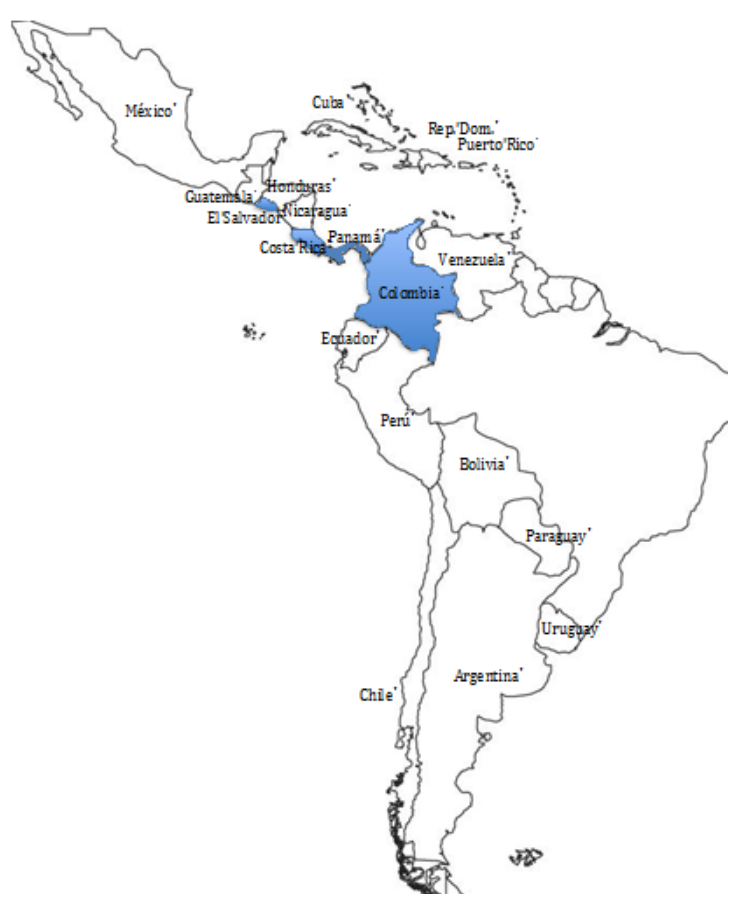

Mapa 9. Países de habla similar, según los costarricenses

En cierto sentido, Costa Rica rompe el ritmo de continuidad que se venía manifestando en todo el Istmo Centroamericano, al no considerar el habla de los nicaragüenses ni la de los hondureños como similar a la suya propia. Un dato interesante, sin embargo, es que los entrevistados compararon a Costa Rica con Colombia, lo cual ya se venía percibiendo desde el siglo XIX, cuando el escritor colombiano José Joaquín Borda visitó Costa Rica y afirmó lo siguiente:

En las conversaciones que tuve con ellos y con los de la capital (San José), noté una perfecta identidad en el acento, lo mismo que en las 
costumbres, con mis paisanos de Cundinamarca y Boyacá. Allí como en estas tierras se acostumbra acentuar los imperativos, usar el vos en lugar de tú y convertir en diptongos, vocales que deben pronunciarse separadas y con distinto acento. "Poné ái los báules, decía un amigo al peón del puerto, mirá que vos sos muy descuidao" (Borda 1865: 123).

En esta comparación, se debe tener en mente que los parecidos corresponden a las variedades costarricense y colombiana habladas en los respectivos altiplanos, tomando en cuenta que el habla costera de ambos países es distinta.

\subsection{PANAMÁ}

Los datos recopilados por Tinoco (2014: 1039-1041) en Panamá apuntan a comparar el habla de este país con las de Venezuela, Colombia y Costa Rica (mapa 10).

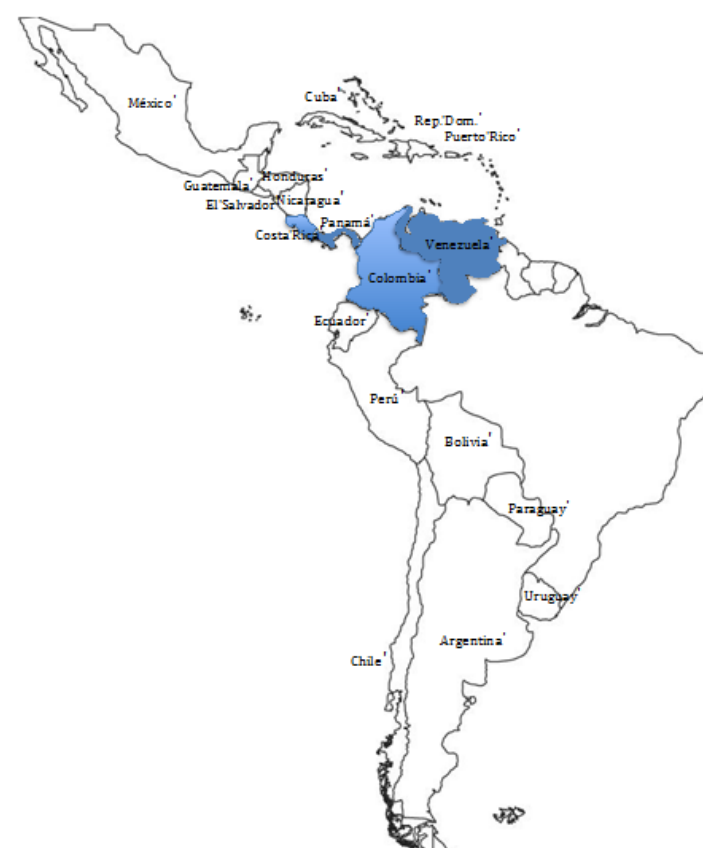

Mapa 10. Países de habla similar, según los panameños 
De acuerdo con Tinoco (2014: 1040),

[1]o anterior confirma el hecho señalado en otras respuestas, acerca de que el panameño tiene en común con el venezolano aspectos culturales, porque ambos son países donde se sintetizan diferentes culturas (en el caso venezolano, la cultura caribeña, la suramericana y la africana, y en el caso panameño, la cultura africana y la caribeña). Esto se observa en lo lingüístico. En las respuestas de los entrevistados se aprecia esto cuando responden: "suenan parecido a nosotros". Le sigue Colombia, con una mención del 14\%. Las circunstancias históricas sin duda nos ligan a este país, y aunque tengamos acentos diferentes, las palabras muchas veces son las mismas. A Costa Rica la pone en tercer lugar un $12,5 \%$ de los entrevistados, quizás por su cercanía. Estos dos últimos países limitan con Panamá: Colombia por el oriente, y Costa Rica, por el occidente. La tendencia a elegir los países que son vecinos y que tienen características caribeñas (salvo Costa Rica) es evidente.

Con Panamá de nuevo se retoma el contínuum lingüístico que se había roto en Costa Rica.

\subsection{Colombia}

Los colombianos entrevistados en Bogotá por Bernal et al. (2014: 228), opinaron que su modo de hablar español se parecía al de México, Venezuela, Ecuador y Panamá (mapa 11). 


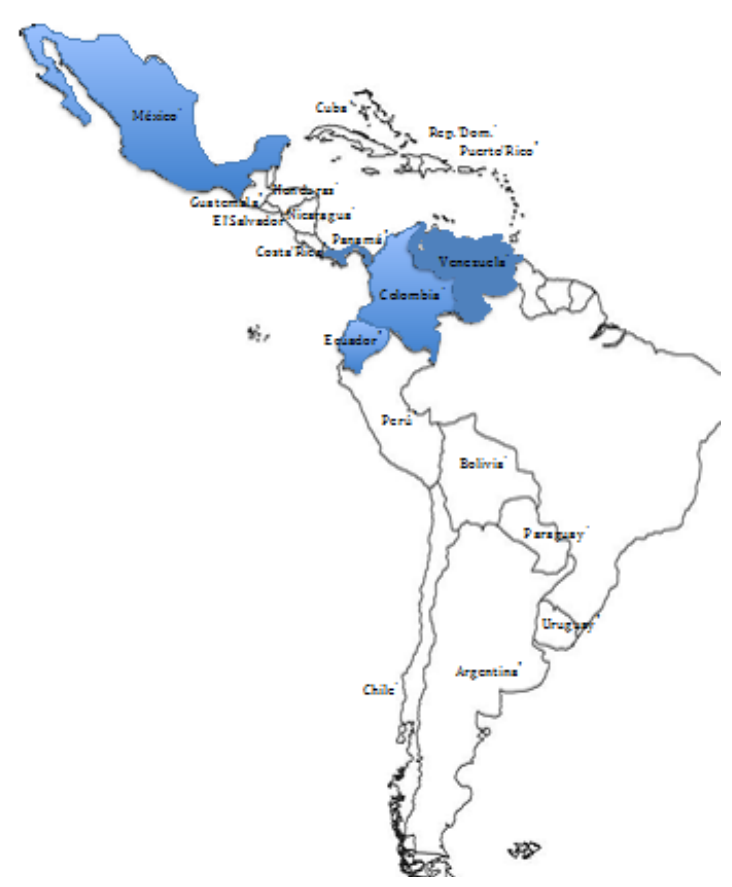

Mapa 11. Países de habla similar, según los colombianos

Al igual que con Costa Rica, el mapa continuado de las similitudes dialectales se pierde con Colombia, pero esta vez a favor de México, país con el cual los entrevistados sentían cercanía.

\subsection{VenEZUELA}

Según el estudio de Coello (2014), entre los caraqueños, la mayor parte de los entrevistados encuentra cercanía dialectal con el habla de Colombia y Panamá (mapa 12). 


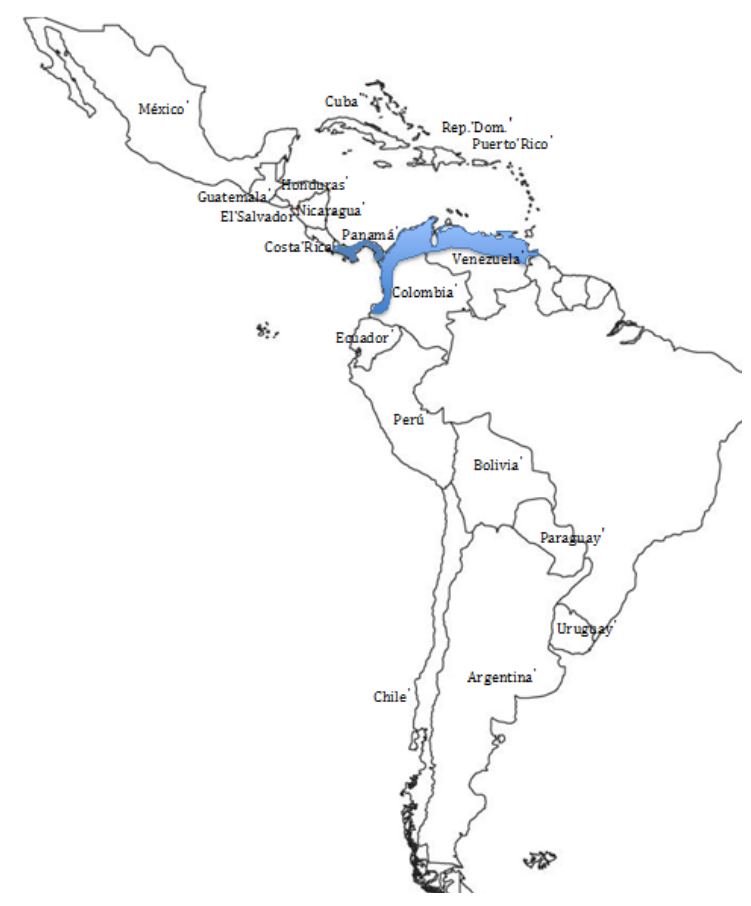

Mapa 12. Países o regiones de habla similar, según los venezolanos

Aquí es menester aclarar, como apunta Coello, que los entrevistados dijeron que el español colombiano que sentían cercano era el de la costa, particularmente el de Cartagena:

Las creencias cognitivas sobre las que se basa la opinión de la semejanza entre la variante colombiana y la venezolana apuntan específicamente a la variante de la costa colombiana, y no a la bogotana. La semejanza se reconoce por una misma manera de hablar, "especialmente en Cartagena"; "específicamente en la costa", y por el uso de "expresiones parecidas" y por "un acento parecido". Finalmente, el caraqueño reconoce como similar la variante panameña, la cual es la más votada en las opciones $1(33 \%)$ y $2(24,3 \%)$.

Lo anterior tiene gran valor porque este parecido entre las hablas caribeñas continentales venía ya documentado desde mediados del siglo XVIII, según testimonio de Jorge Juan y Antonio de Ulloa, dos ingenieros españoles que recorrieron en viaje de investigación las costas de Venezuela, Colombia y Panamá (se respeta la ortografía original): 
Aunque no noté en Cartagena lo que voy a decir, fue por tenerlo reservado para este lugar; y es, que assí en aquella Ciudad, como en Portobelo, y esta [ciudad de Panamá] tienen sus moradores un methodo de prorrumpir las palabras, quando hablan, bien particular; y assí como hay unos Pueblos, que tienen arrogancia; otros dulzura; y otros brevedad; este tiene una floxedad, y desmayo en las vocales tal, que es muy sensible, y molesto al que le oye, hasta que la costumbre le va habituando a ello: aun mas sucede en este particular, y es que en cada una de las tres ciudades llevan distinto methodo en el desquadernamiento, flaqueza, y acento de las voces, acompañado de diversas sylabas propias de cada uno; no menos distinguibles entre sì, que todas ellas apartadas del estilo, con que se habla en España (Juan 1748: Parte I, libro II, cap. III; pág. 163-164).

Al igual que Juan y Ulloa, los entrevistados por Coello opinaron que el parecido se debía a expresiones similares y a un acento parecido.

Como dato digno de apuntar, se observa que los venezolanos no sienten parecido lingüístico con los caribeños insulares, al contrario de lo que estos opinan, según se vio en páginas anteriores.

\subsection{ECUADOR}

Los habitantes de Quito entrevistados por Flores (2014: 457-461) opinaron que los países que hablaban similarmente a ellos eran Perú, Colombia, Venezuela, Bolivia y México (mapa 13). 


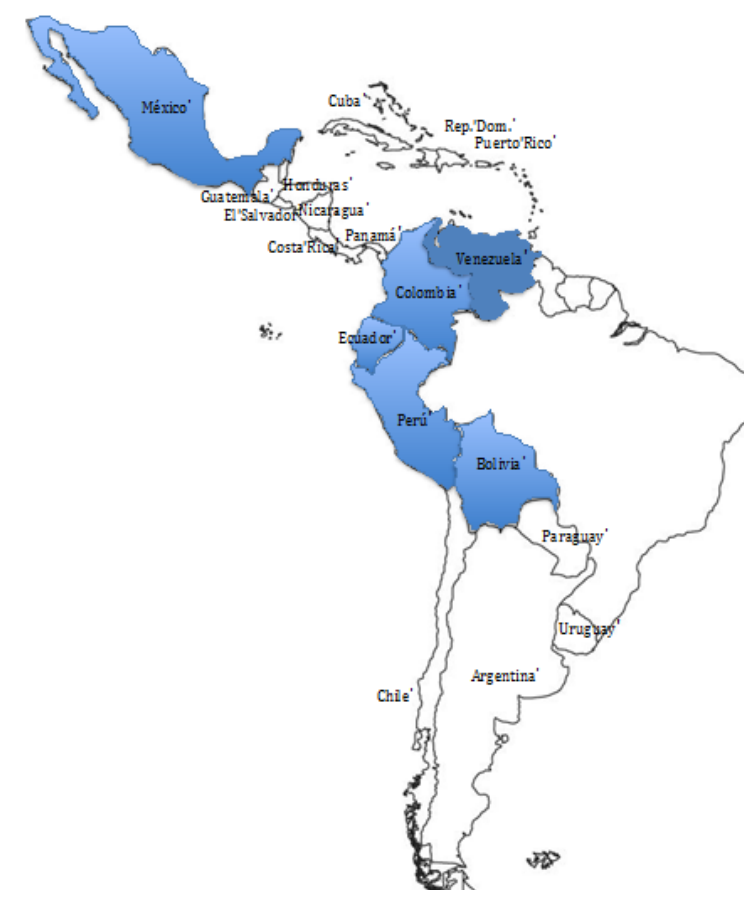

Mapa 13. Países de habla similar, según los ecuatorianos

Como se puede observar, también Ecuador rompe en buena medida con el esquema del contínuum dialectal perceptual, al opinar que México está dentro de los países con habla similar a la suya propia. De acuerdo con Flores, "las personas con estudios universitarios incluyen a México en esta relación y sostienen que este dialecto es fácilmente reconocible y se identifican con él por todo el conocimiento que tienen, gracias a los doblajes de las películas" (2014: 461).

Además, tal como sucede en general con las percepciones dialectales, Flores (ibídem) apunta que "[a]lgunas razones argumentadas son extralingüísticas: 'son parecidos a nosotros'; 'tenemos las mismas costumbres y pensamientos'; y otras sí son de conocimiento lingüístico: 'tenemos el mismo vocabulario'; 'tenemos el mismo acento",. 


\subsection{PeRÚ}

Las personas entrevistadas en Lima opinaron, según los estudios de Arias (2014), que el habla suya guarda similitud o cercanía con Ecuador, Colombia y México (mapa 14).

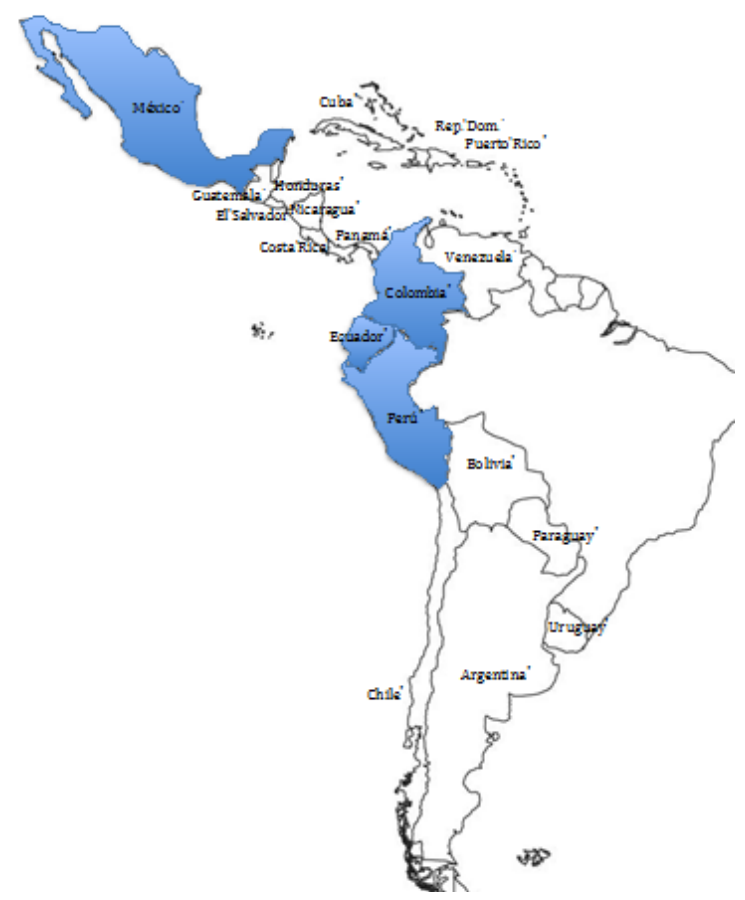

Mapa 14. Países de habla similar, según los peruanos

Según los datos de Arias en cuanto a las preferencias de los limeños por los países arriba mencionados,

[1]os informantes consideran que Ecuador tiene una pronunciación parecida a la peruana, es decir, los mismos sonidos; que en ese país se habla "correctamente"; que se diferencian solo por el dejo, no muy marcado, sino más neutral, y que los dos países tienen una cultura parecida, similitudes en la forma de expresarse, de mostrar cordialidad y porque comparten vecindad. En el caso de Colombia, se prefiere por la pronunciación clara, por tener los mismos sonidos y parecida entonación; por compartir parte del léxico y por el hecho de tener raíces y culturas parecidas, además de contacto cercano. En el caso de México, se prefiere 
por ser esta la variedad más conocida, por entender parte del léxico de uso común y compartir muchas palabras, por no tener dejo marcado y por tener cultura parecida y similitudes en la forma de expresarse.

Llama la atención el hecho de que los entrevistados peruanos sintieran similitud con México, pero no con los bolivianos, como fue el caso de los ecuatorianos. Esto en razón de la proximidad geofísica y cultural que podría mediar por ser países de la zona andina.

\subsection{BOLIVIA}

Para los entrevistados en La Paz, capital de Bolivia, y de acuerdo con los datos entresacados del estudio de Aguilar (2014: 100-101), los países que se asemejan a su propia habla son Perú, México y Ecuador (mapa 15).

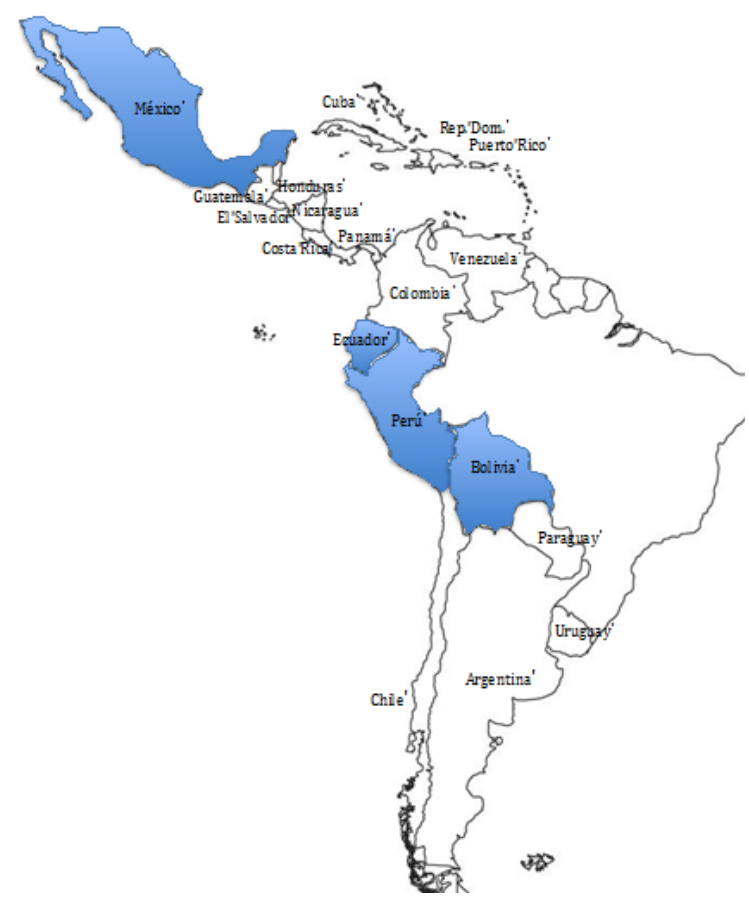

Mapa 15. Países de habla similar, según los bolivianos 
Tal como opina Aguilar, se entiende que los entrevistados de La Paz hayan escogido a Ecuador como al Perú, por ser países cercanos a Bolivia. Pero con México el panorama cambia, y las razones aducidas por los consultados son:

[L]os informantes se identifican más con el habla de este país que con la de otras regiones más cercanas, posiblemente por la producción audiovisual mexicana que se conoce en Bolivia. La influencia de los medios es un factor importante para esta percepción y, por supuesto, los aspectos culturales que comparten ambos países (Aguilar 2014: 100).

\subsection{Paraguay}

De acuerdo con el estudio de Chiquito y Saldívar (2014), las hablas hispanas que los entrevistados de Asunción, la capital del Paraguay, sienten como cercana a la suya son las de Argentina, Uruguay, Chile y México (mapa 16).

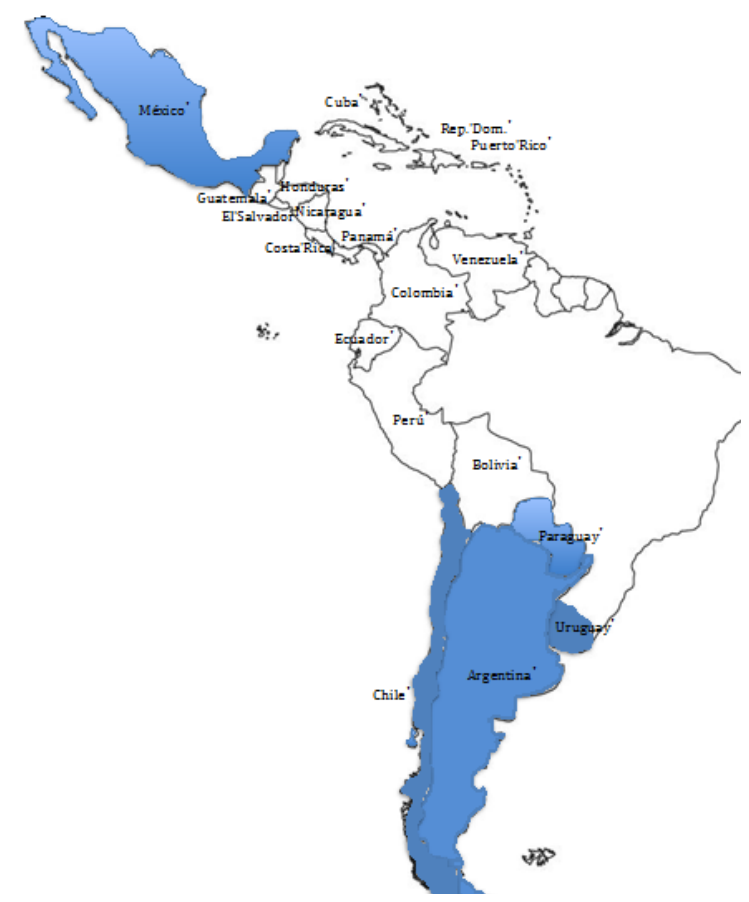

Mapa 16. Países de habla similar, según los paraguayos 
Como se puede apreciar, los paraguayos sienten a Uruguay, Argentina y Chile como de habla similar, pues, tal como afirman Chiquito y Saldívar (ibíd.),

Argentina, por ser país vecino con importantes ciudades fronterizas, es considerado modelo del habla española [...] precisamente por su cercanía geográfica. El que Uruguay y Chile reciban porcentajes relativamente altos, completa la percepción de que los informantes ven el español paraguayo como parte de una variante común del Cono Sur.

Cosa distinta surge con respecto a México, ya que, como aducen las autoras (ibídem),

[e]n la primera mención entre los países de habla castellana similar a la paraguaya aparece México (39,8\%), una elección que no parece tener una razón plausible, excepto cuando se estudian las explicaciones que exponen los entrevistados; de estas se infiere que esta elección coincide con las apreciaciones del español mexicano en los medios de comunicación, en los que, según los informantes, ese país comparte con Paraguay la característica de "no tener acento" en el habla española.

\subsection{CHILE}

Las entrevistas llevadas a cabo en Santiago de Chile por Rojas (2014) indican que los países con los cuales los chilenos se sienten cercanos lingüísticamente son Perú, Bolivia y Argentina (mapa 17). 


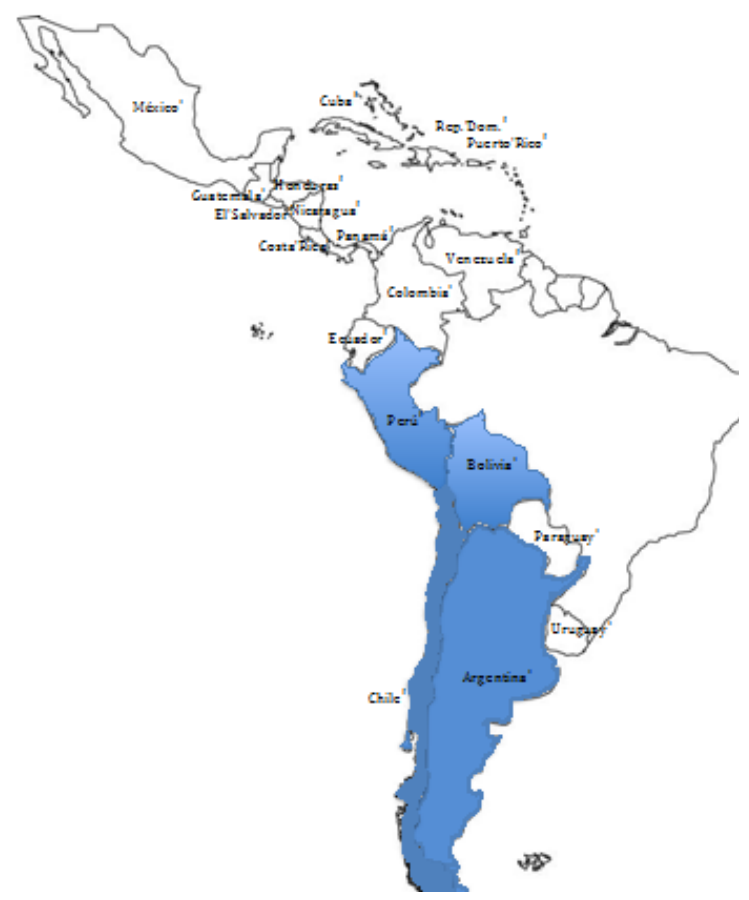

Mapa 17. Países de habla similar, según los chilenos

De lo anterior se infiere que los entrevistados aplicaron el principio de la proximidad, tal como lo explica Rojas:

En general, se puede observar que los países que tienen más menciones son los geográficamente contiguos o próximos a Chile (la mayoría de Sudamérica: Perú, Bolivia y Argentina); a la inversa, los países que son mencionados en menos ocasiones son los más lejanos (Rojas 2014: 161).

A pesar de lo anterior, Rojas (ubi supra) apunta que "[e]n este ítem las preferencias se encuentran muy disgregadas, por lo cual no podemos hablar con certeza acerca de preferencias mayoritarias".

Por otra parte, es significativo el hecho de que, según lo indicado por Rojas, el segundo grupo de preferencias apunta a que "ningún país tiene una forma de hablar español que es parecida a la de Chile (14\%)" (2014: 161). 


\subsection{Argentina}

Los informes que dan Llull y Pinardi (2014: 45-46) acerca de los países que consideran los entrevistados en Argentina como similares a su propia habla, fue prácticamente uno solo: Uruguay. Luego, a gran distancia, colocaron a Chile (mapa 18).

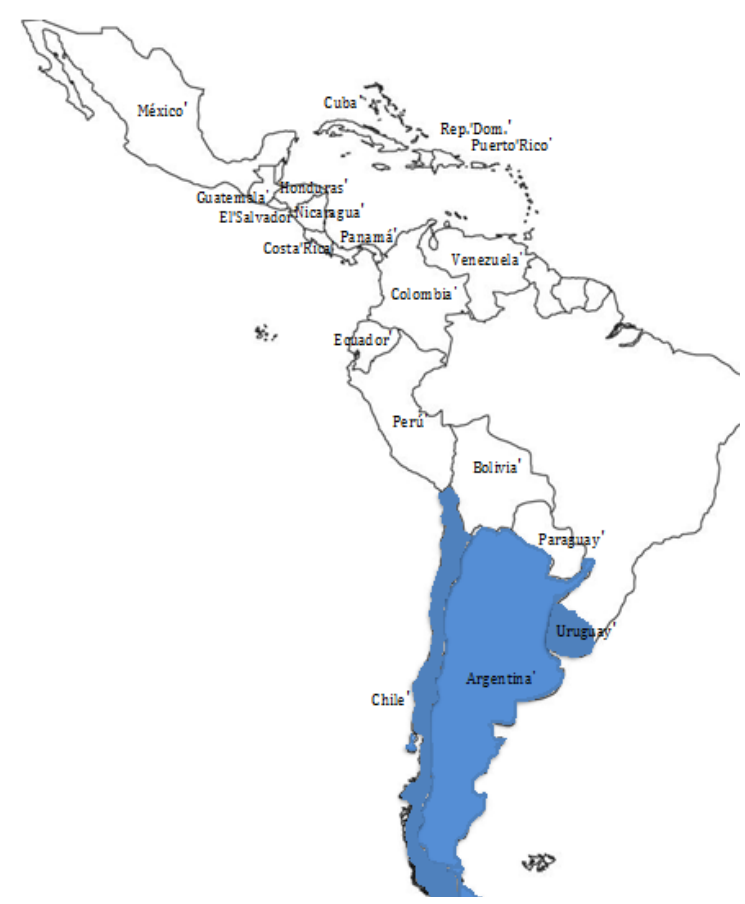

Mapa 18. Países de habla similar, según los argentinos

Siguiendo las afirmaciones de las investigadoras mencionadas,

[c]omo resulta evidente, la gran mayoría (tres cuartas partes del total) se inclina por Uruguay al momento de encontrar similitudes con el habla propia (primera alternativa). Con mucho menos valor estadístico, Chile aparece como segunda opción, con porcentuales que se ubican en menos de la mitad de los detectados para el primer caso (Uruguay). Finalmente, con muy escasa participación, en tercer término predomina la opción ninguno (Llull y Pinardi 2014: 45). 


\subsection{URUGUAY}

Según el trabajo de investigación de García, los uruguayos entrevistados en Montevideo indicaron a la Argentina como el país con el cual guardan mayor similitud lingüística (mapa 19).

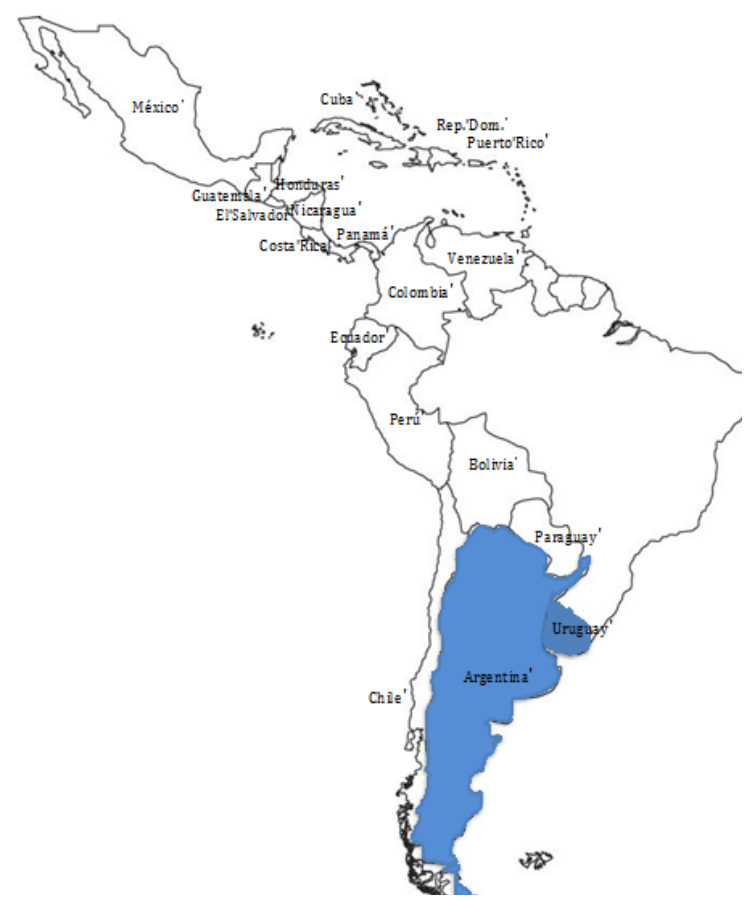

Mapa 19. Países de habla similar, según los uruguayos

De acuerdo con los datos suministrados por García, el porcentaje de opiniones respecto de Argentina fue tan alto (casi un 90\%), que perfectamente se podría afirmar que no existe otro país de preferencia por los entrevistados, que sea digno de ser representado en un mapa dialectológico perceptual. 


\section{ANÁLISIS DE CONJUNTO}

Empezando de norte a sur, ninguno de los países centroamericanos, ni México, mencionó a otros países fuera del Istmo Centroamericano dentro de los que consideraban países de habla similar. En consecuencia, todo el Caribe y toda la América del Sur quedó como una zona de habla distinta a México y América Central. Por otra parte, ningún país del Caribe ni de América del Sur considera que tiene un habla similar con algún país centroamericano (con excepción de los panameños), con lo cual se podría hablar de una zona norte, con México, y centroamericana autónoma, independiente del resto de países americanos. A su vez, México y el conjunto de países centroamericanos (Guatemala, El Salvador, Honduras, Nicaragua, Costa Rica y Panamá) va formando una especie de gradación dialectal, de acuerdo con la cual, cada país ve similitudes con los países más cercanos, pero dejando de lado los que se alejan del país en cuestión.

En este sentido, no se podría hablar de una única zona dialectal perceptual centroamericana, ya que ninguno de los países mencionó el conjunto de naciones del Istmo Centroamericano como una zona autónoma, sino los que estaban más cercanos. Así, los guatemaltecos consideran a México y a El Salvador como de habla similar; los salvadoreños consideran a los guatemaltecos, a los hondureños y a los nicaragüenses como de habla similar, pero ya no a los mexicanos. Por su parte, hondureños y nicaragüenses señalaron a todos los países centroamericanos menos a Panamá como de habla similar, mas los costarricenses sí opinaron que Panamá -y Colombiaeran de habla similar, pero no el resto. En cuanto a Panamá, los entrevistados consideraron que Costa Rica y Colombia se asemejaban a su habla, pero no el resto de países hacia el norte del Istmo. Y así sucesivamente.

En lo concerniente al Caribe, los tres países antillanos -Cuba, República Dominicana y Puerto Rico- ven similitudes entre sí, de modo que se podría hablar de un conjunto dialectal perceptual, con lo cual no se puede afirmar que haya diferencias entre sí, como sucede con el Istmo Centroamericano. Además, y a diferencia de los centroamericanos, los caribeños opinaron que dos países fuera de su región tenían similitudes con ellos, los cuales son Panamá y Venezuela, razón por la cual se consideran como parcialmente similares. Fuera de estos, ningún país fue mencionado como de habla similar, con lo cual se podría trazar un mapa perceptual caribeño insular y continental.

Respecto de América del Sur, los colombianos y los venezolanos forman una especie de transición entre el Istmo Centroamericano, el Caribe insular y América del Sur, al señalar ambos similitudes entre sí y con Panamá, pero no con el resto de los países suramericanos ni centroamericanos. 
Además, desde Ecuador hasta Bolivia se observa una especie de zona dialectal perceptual que tiene su frontera en las tierras bajas de Colombia, pero que se detiene en Bolivia, lo cual da pie para dividir una región, la andina, del resto; o sea, del Cono Sur.

Por otra parte, los países del Cono Sur ven similitudes entre sí, de modo que se podría hablar, a grandes rasgos, de una zona dialectal perceptual sureña (mapa 20).

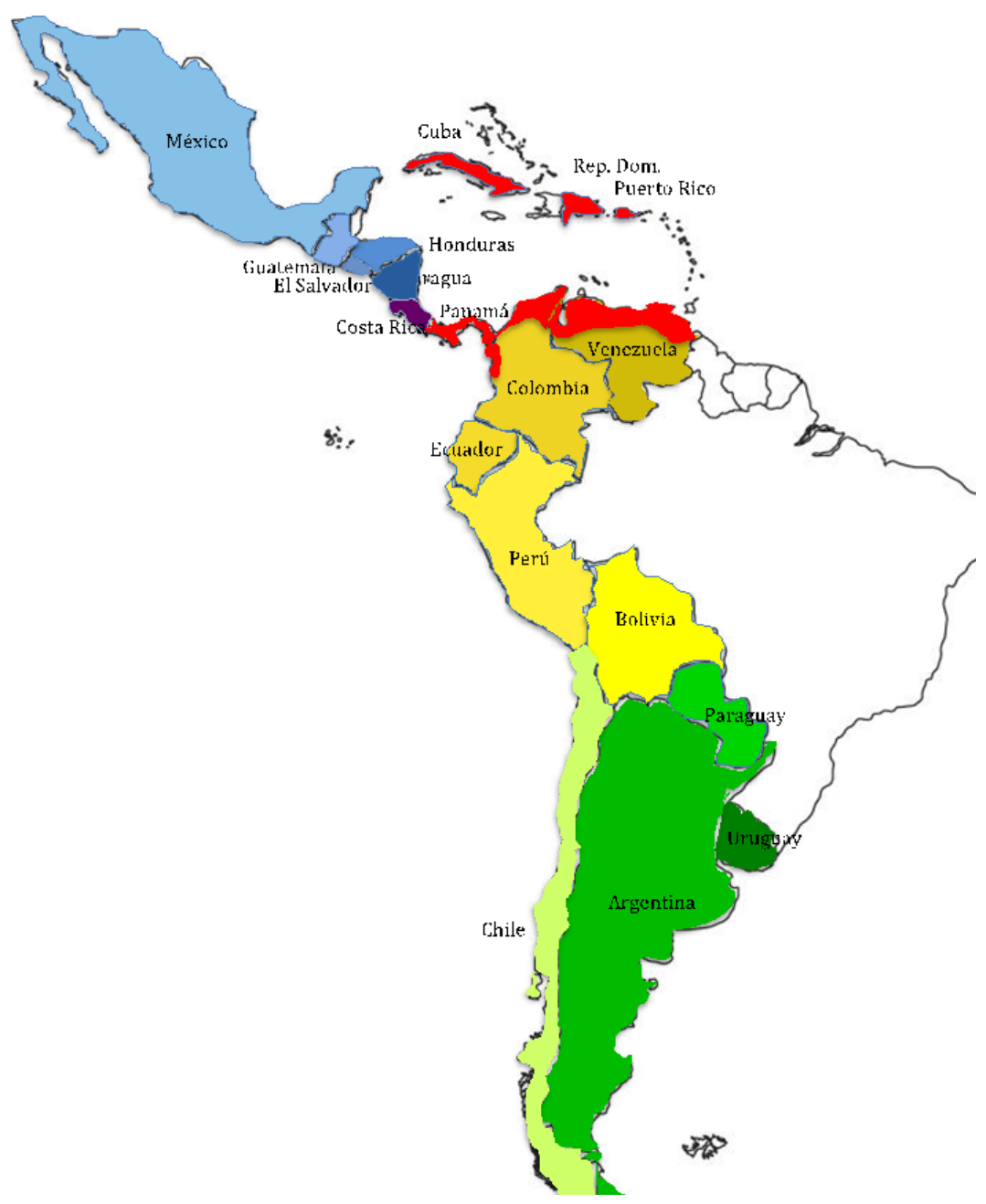

Mapa 20. División dialectal perceptual de América

(eje de la reciprocidad) 
Del resumen anterior se observan cuatro puntos dignos de tomar en cuenta. En primer lugar, se cumple el principio de la proximidad, expuesto por Montgomery, de acuerdo con el cual "when respondents are asked to draw maps of regions or dialect areas, they tend to most frequently draw areas local to themselves"(2012: 639). De esta forma, y aplicado a Hispanoamérica, se puede afirmar, en general, que un país ve similitudes con su país vecino, y así sucesivamente, de norte a sur del continente americano.

En segundo lugar, y en concatenación con lo anterior, se observa que los entrevistados ven similitudes que van formando una especie de contínuum, de acuerdo con el cual, A se parece a B, B se parece a $\mathrm{C}$ y C a D, pero A no se parece a D. En este caso, se podría hablar de un contínuum dialectal perceptual.

En tercer lugar, estamos frente a un nuevo fenómeno, el cual he dado en llamar los parámetro de la reciprocidad y de la no reciprocidad. El eje de la reciprocidad consiste en que el hablante de un país A ve similitudes con los hablantes de un país B y viceversa; los del país B sienten lo mismo respecto del país A. Lo anterior se puede observar, por ejemplo, con países como Guatemala, Honduras y El Salvador, los cuales sienten que hablan similarmente unos con otros, o con las islas antillanas (Cuba, República Dominicana y Puerto Rico). El segundo parámetro, de la no reciprocidad, radica en que A percibe similitudes con B pero no B con A. Esto se da, por ejemplo, en Guatemala, cuyos entrevistados mencionaron a Costa Rica como de habla similar, pero los entrevistados de Costa Rica no percibieron que hablaran similarmente a los guatemaltecos; o bien, con los costarricenses, los cuales perciben similitudes con los salvadoreños, pero no viceversa. También se nota en el panorama general suramericano, al mencionar los colombianos, los ecuatorianos, los peruanos, los bolivianos y los paraguayos, grandes similitudes con México, pero ninguno de los mexicanos entrevistados percibió similitudes con los países suramericanos. Para poder comprender esta ruptura en la reciprocidad, habrá que considerar factores culturales, y que quizá tengan que ver con el prestigio lingüísticos. A manera de ejemplo, se sabe que los mexicanos tienen ya una tradición relativamente larga y extensa de ser exportadores de cultura lingüística propia a través de la música, el cine y la televisión, lo cual pudo haber influido en la percepción de otros hablantes (Cuadro 1). Asimismo, se podría explicar por razones históricas, ateniéndonos a la clásica división dialectal entre tierras altas y tierras bajas del continente americano, proclamada por Max L. Wagner (1920), como se verá más adelante. Por otra parte, hay países que se mencionaron en varias ocasiones como similares a zonas relativamente distintas, como es el caso de Panamá, que figura como de habla similar a los países antillanos, pero también a Costa Rica y a Colombia. 
Cuadro 1. Similitudes perceptuales por países (cuadro general)

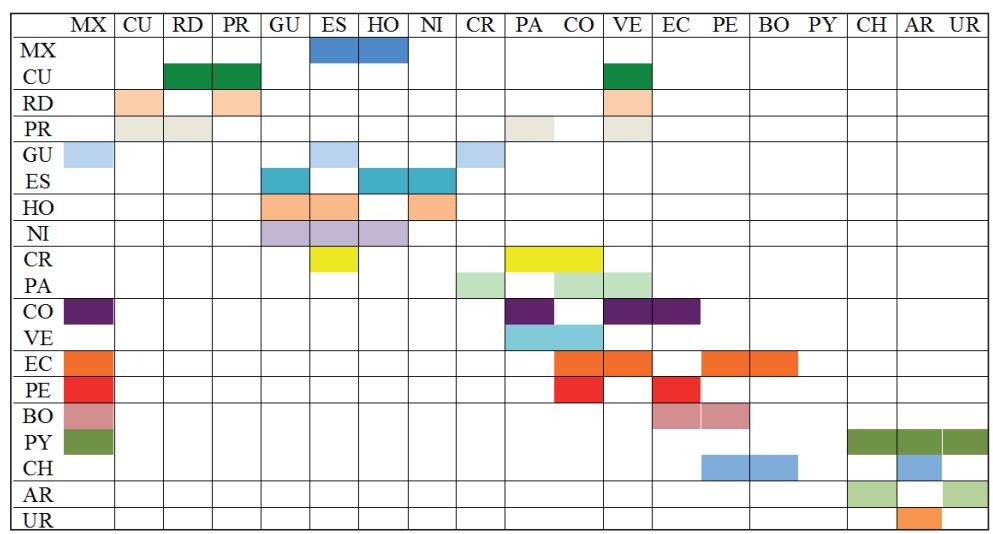

Por último, si nos valemos del eje de la reciprocidad (Cuadro 2), se observan ciertos conglomerados geo-perceptuales que podrían, en principio, subdividir al continente americano en cinco regiones:

1. México y parte norte de América Central (Guatemala, El Salvador, Honduras y Nicaragua).

2. Parte sur de América Central (Costa Rica y Panamá), más parte norte de América del Sur (regiones interiores de Colombia y Venezuela).

3. El Caribe insular, más Panamá, y las costas de Colombia y Venezuela.

4. La Región Andina.

5. El Cono Sur.

Cuadro 2. Similitudes perceptuales por países (eje de la reciprocidad)

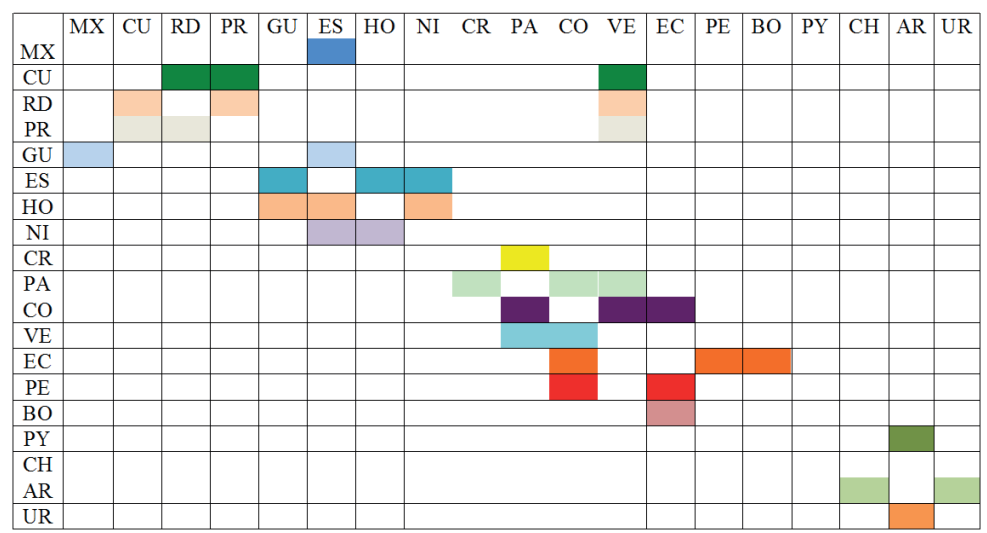




\section{DIVISIÓN DIALECTAL DE AMÉRICA SEGÚN LOS LINGÜISTAS}

Son varios los investigadores que han intentado dividir y subdividir todo el continente americano en zonas dialectales, en cuyos trabajos se desea dar una visión global, de conjunto, de los rasgos que caracterizan el español del Nuevo Mundo, a la vez que se señalan subáreas lingüísticas (cfr. Moreno 1993: 11-37). Entre los más sobresalientes tenemos los que se citan a continuación, ordenados cronológicamente.

Lo que se podría catalogar como prehistoria en el reconocimiento de zonas dialectales en América lo representa el cubano Juan Ignacio de Armas y Céspedes, en 1882, cuya intención, según Zamora y Guitart (1988: 177178), era demostrar que el español en América tendería al fraccionamiento, y que las lenguas antillanas no tuvieron influjo sobre el español, para lo cual inventa falsas etimologías de auténticas voces antillanas (mapa 21).

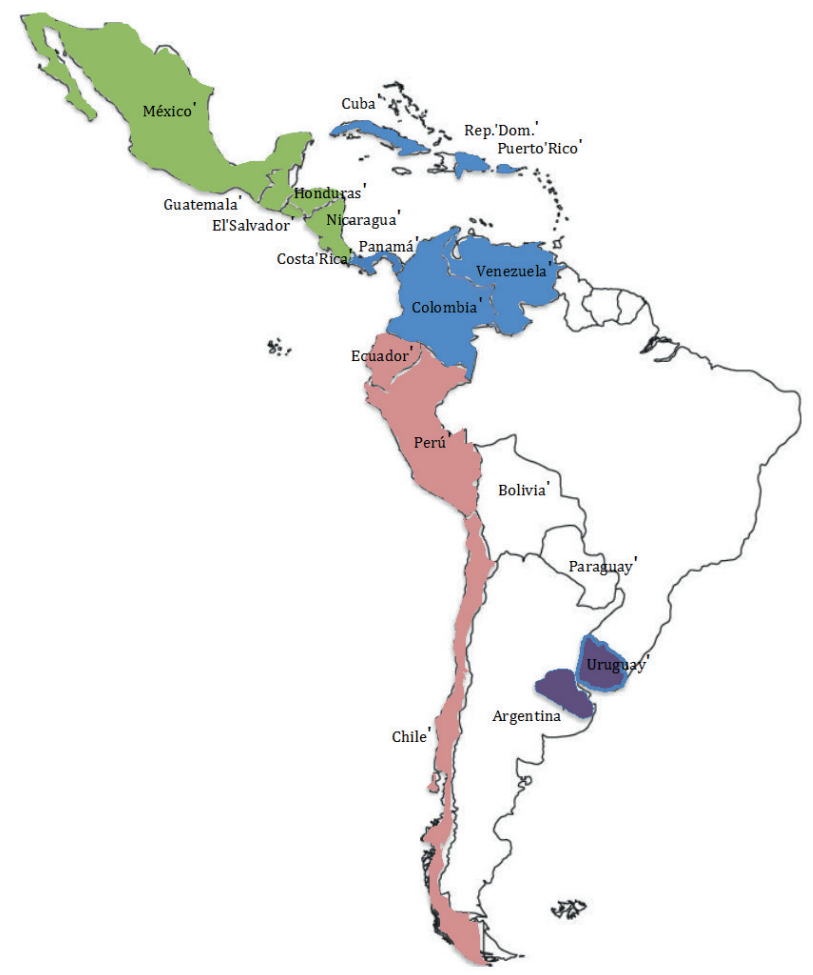

Mapa 21. División dialectal de América, según J. Armas Céspedes (1882) 
Armas y Céspedes propone, con todo, cuatro zonas dialectales en América:

1. Antillas, Venezuela, Colombia (incluida Panamá) y cierta parte de América Central (pero no dice cuál).

2. México y la otra parte de América Central (sin especificar).

3. El Pacífico (sin especificar).

4. La región rioplatense (Buenos Aires).

La segunda persona en interesarse por una división dialectal de América es Max Leopold Wagner (1920), el cual por primera vez propone una división entre las tierras altas o interiores del Nuevo Mundo y las tierras bajas o costeras (mapa 22).

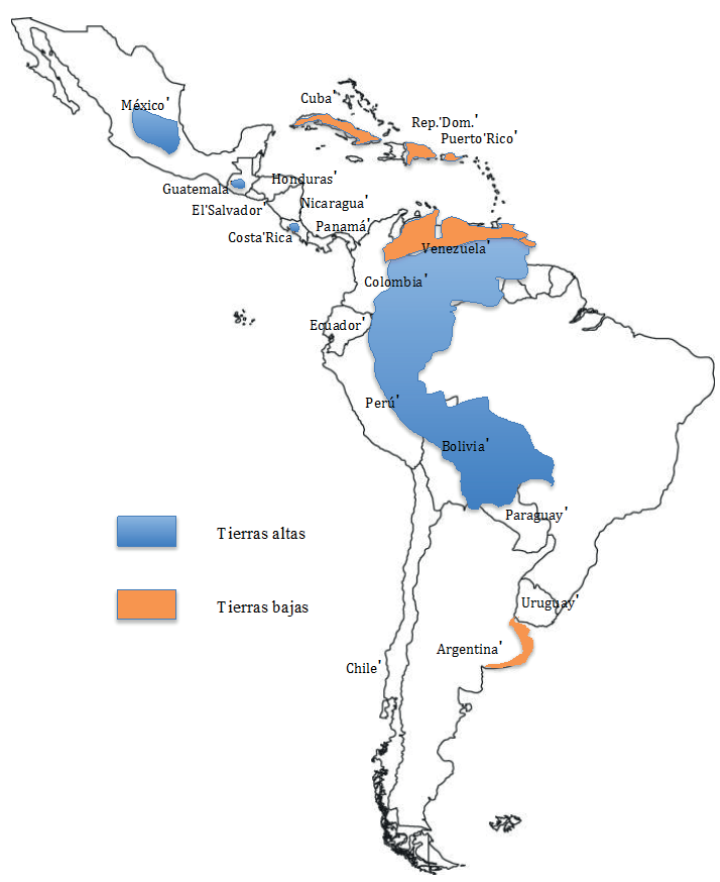

Mapa 22. División dialectal de América, según Max L. Wagner (1920)

Según Wagner, tal división obedece a la colonización inicial del Nuevo Mundo, propiciada en su mayor parte por pobladores andaluces: 
Observando con detenimiento, notamos que los países y regiones con carácter lingüístico meridional español son las regiones pobladas primero y más persistentemente. En primer lugar las Antillas [...] luego la costa atlántica de México, Colombia, Venezuela [...] en Argentina igualmente en la costa [...] Son diferentes, empero, las condiciones de poblamiento en el interior de México, América Central, Venezuela, Colombia, Perú, Ecuador y Bolivia, donde el español se introdujo lentamente (Wagner 1920: 295; traducción propia).

Las tierras altas o interiores se oponen a las bajas o costeras en una serie de rasgos fonéticos, como el tratamiento de /s/, /R/, /1/ y /n/ implosivas, y de /d/ intervocálica. Así, las tierras bajas presentan un influjo meridional peninsular más marcado que las altas. Dicha bipartición dialectal obedece a dos factores históricos: durante las primeras décadas de la conquista de América la empresa estuvo en manos de andaluces; luego, la flota que unió durante la Colonia a España con América partía principalmente de Sevilla y estaba controlada por españoles del Sur.

En 1962, Ramón Menéndez Pidal desarrolló con mayor detenimiento la teoría expuesta por Wagner respecto de la oposición entre tierras altas o interiores y tierras bajas o costeras (Menéndez Pidal 1962: 164-165). Wagner y Menéndez Pidal concuerdan en que los andaluces son los responsables de la macrodivisión del español americano en tierras altas o interiores y tierras bajas o costeras (mapa 22).

En 1921, Pedro Henríquez Ureña dio a conocer lo que se puede considerar el primer intento definido de caracterización dialectal de América, bajo tres criterios: geográfico, político-cultural y de sustrato o de contacto lingüístico. Las zonas que, como dice Henríquez Ureña (1921: 360), "provisionalmente me arriesgo a distinguir en la América española”, son cinco (mapa 23): 


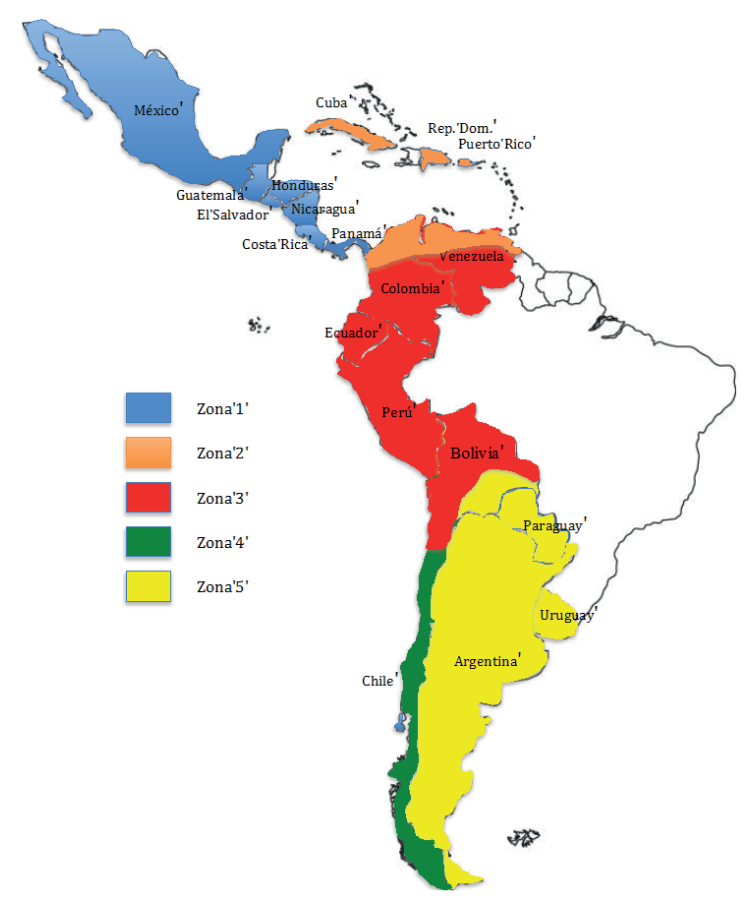

Mapa 23. División dialectal de América, según P. Henríquez Ureña (1921)

1. La que comprende las regiones bilingües del sur y sudoeste de los Estados Unidos, México, y las repúblicas de América Central.

2. Las tres Antillas españolas (Cuba, Puerto Rico y la República Dominicana, la antigua parte española de Santo Domingo), la costa y los llanos de Venezuela y probablemente la porción septentrional de Colombia.

3. La región andina de Venezuela, el interior y la costa occidental de Colombia, el Ecuador, el Perú, la mayor parte de Bolivia y tal vez el norte de Chile.

4. La mayor parte de Chile.

5. La Argentina, el Uruguay, el Paraguay y tal vez parte del sudoeste de Bolivia.

En 1962, Lincoln Canfield (1988: 21) parte de criterios lingüístico-históricos para dividir las regiones americanas en tres etapas, según el grado de influencia del andaluz a que fueron expuestas durante la Colonia (mapa 24): 


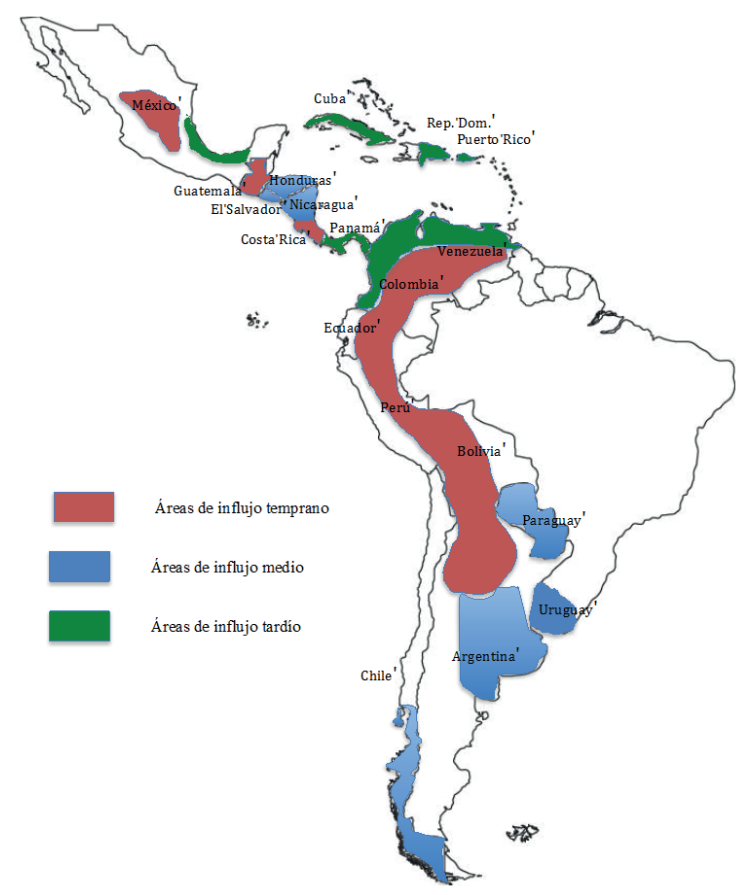

Mapa 24. División dialectal de América, según L. Canfield (1962)

1. Áreas de influjo temprano (1550): México (tierras altas), Guatemala, Costa Rica, tierras altas de Colombia, Ecuador, Perú y Bolivia, noroeste de Argentina y frontera sur de Estados Unidos.

2. Áreas de influjo medio (1650): Nuevo México, Colorado, El Salvador, Honduras, Nicaragua, Paraguay, Uruguay, oeste y zona porteña de Argentina, además del sur de Chile.

3. Áreas de influjo tardío (1750): Cuba, Puerto Rico, República Dominicana, México (Parroquia de San Bernardo, Tabasco, Veracruz), Panamá, costa de Colombia, casi toda Venezuela e inmigrantes de Nueva York y Florida.

En 1964, José Pedro Rona sugirió una división dialectal de América basada en los siguientes correlatos fonéticos y morfológicos (220-224):

1. Zonas yeístas y žeístas: Uruguay.

2. Zonas yaístas y no žeístas: México. 
3. Zonas no yeístas y žeístas: Paraguay.

4. Zonas no yeístas y no žeístas: Sur de Perú.

5. Voseo del tipo A (-áis, -éis, -is).

6. Voseo del tipo B (-áis, -is, -is).

7. Voseo del tipo C (-ás, -és, -is).

8. Voseo del tipo D (-ás, és, -es [desinencias átonas]).

De la combinación de los cuatro rasgos anteriores, Rona obtuvo las siguientes 16 zonas dialectales (mapa 25, Cuadro 3):

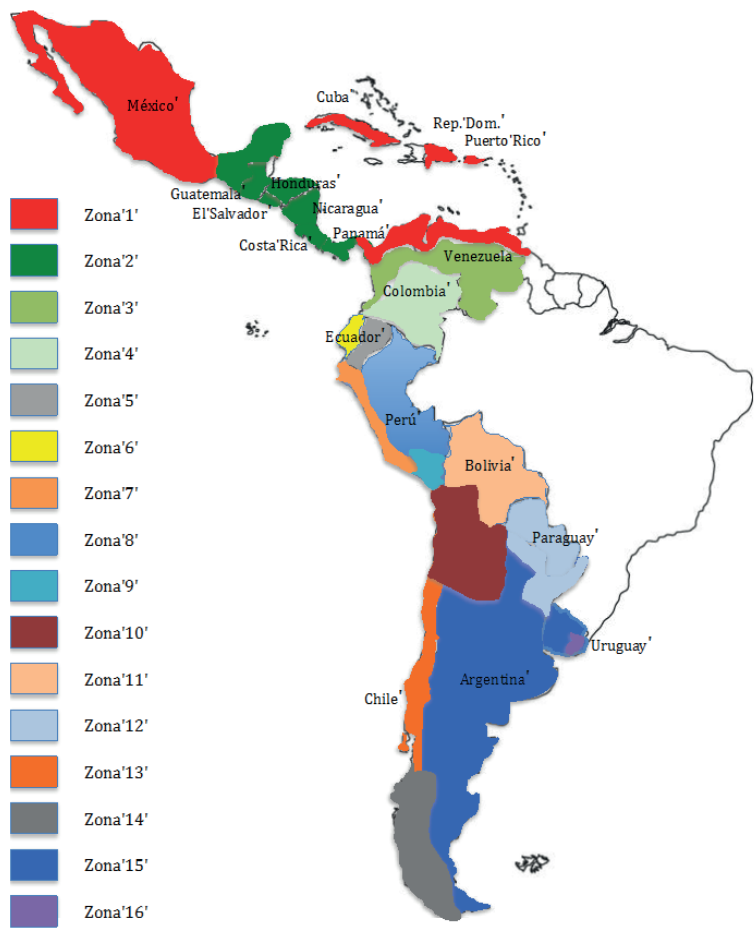

Mapa 25. División dialectal de América, según P. Rona (1964) 
Cuadro 3. Zonas dialectales de América, según P. Rona (1964: 222-224)

\begin{tabular}{|c|c|c|c|c|c|}
\hline & Zona & Yeísmo & Žeísmo & Voseo & Forma \\
\hline 1. & $\begin{array}{l}\text { México (excepto los Estados de Chiapas, } \\
\text { Tabasco, Yucatán y Quintana Roo, } \\
\text { Antillas, la costa atlántica de Venezuela y } \\
\text { Colombia, mitad oriental de Panamá }\end{array}$ & sí & no & no & - \\
\hline 2. & $\begin{array}{l}\text { Los estados mexicanos citados, con } \\
\text { América Central, incluida la mitad } \\
\text { occidental de Panamá }\end{array}$ & sí & sí & sí & $\mathrm{C}$ \\
\hline 3. & $\begin{array}{l}\text { Costa pacífica de Colombia y el interior } \\
\text { de Venezuela }\end{array}$ & sí & no & sí & $\mathrm{C}$ \\
\hline 4. & Zona andina de Colombia & no & no & sí & $\mathrm{C}$ \\
\hline 5. & Zona andina de Ecuador & sí & sí & sí & $\mathrm{C}$ \\
\hline 6. & Zona serrana de Ecuador & no & sí & sí & B \\
\hline 7. & Zona costera del Perú, excepto sur & sí & no & no & - \\
\hline 8. & Zona andina del Perú & no & no & no & - \\
\hline 9. & Zona meridional del Perú & sí & no & sí & $\mathrm{B}$ \\
\hline 10. & $\begin{array}{l}\text { Norte de Chile, noroeste de la Argentina } \\
\text { y los Departamentos bolivianos de Oruro } \\
\text { y Potosí }\end{array}$ & no & no & sí & B \\
\hline 11. & El resto de Bolivia & no & no & sí & $\mathrm{C}$ \\
\hline 12. & $\begin{array}{l}\text { Paraguay (excepto la zona de Concepción) } \\
\text { y las provincias argentinas de Misiones, } \\
\text { Corrientes y Formosa }\end{array}$ & no & sí & sí & $\mathrm{C}$ \\
\hline 13. & El centro de Chile & sí & no & sí & $\mathrm{B}$ \\
\hline 14. & $\begin{array}{l}\text { El sur de Chile y una pequeña porción de } \\
\text { la Patagonia argentina }\end{array}$ & no & no & sí & $\mathrm{B}$ \\
\hline 15. & $\begin{array}{l}\text { Las provincias "gauchescas" de la } \\
\text { Argentina (aproximadamente, Buenos } \\
\text { Aires, Entre Ríos, Santa Fe, La Pampa, Río } \\
\text { Negro, Chubut y hasta la Tierra del Fuego) } \\
\text { y el Uruguay (excepto la zona serrana y } \\
\text { la fronteriza) }\end{array}$ & sí & sí & sí & $\mathrm{C}$ \\
\hline 16. & $\begin{array}{l}\text { Zona ultraserrana del Uruguay } \\
\text { (Departamentos de Rocha y Maldonado } \\
\text { y parte de Lavalleja y Treinta y Tres) }\end{array}$ & sí & sí & no & - \\
\hline
\end{tabular}


Rona (1964: 223) distingue otras siete zonas, las cuales, según él, tienen otro componente no contemplado en las zonas anteriores, cual es el contacto lingüístico. Para efectos del presente estudio, no se han tomado en cuenta 5 .

En 1975, Melvyn Resnick publicó el primer estudio global del español americano con datos exclusivos del nivel fonético. Su obra comprende un extenso corpus de cruces de variables tras los que llega a determinar, mediante oposiciones binarias (+ -), 256 tipos de combinaciones fonéticas, pero ningún mapa dialectal; pues, según el mismo autor apunta, "it is important to note that the successful organization and comparison of phonological dialect data does not necessarily require the classification of the dialects into zones" (Resnick 1975: 5).

Resnick trabajó con cuestionarios dirigidos, poniendo a los informantes a leer frases. Con lo anterior, obtuvo los siguientes ocho rasgos fonéticos (Resnick 1975: 7):

1. Realización de /s/ (en palabras como estados).

2. Realización de /r/ (perro).

3. Realización de /x/ (mujer).

4. Yeísmo (calló, cayó).

5. Oclusivas tras lateral (el bebé).

6. Realización de /n/ final (corazón).

7. Alternancias de líquidas ( $m a r, m a l)$.

8. Ensordecimiento vocálico (leche).

En 1979, Zamora (citado en Zamora y Guitart 1988: 182-183) propone una nueva división dialectal, esta vez basada en únicamente tres rasgos: el fonema fricativo alveolar sordo /s/ en posición posnuclear, el fonema fricativo velar sordo $/ \mathrm{x} / \mathrm{y}$ el voseo, de cuyos resultados obtiene nueve zonas dialectales (mapa 26, Cuadro 4).

5 Razón por la cual he incluido el Departamento de Concepción, en el Paraguay, en el mapa 25, sin dejarlo por fuera, tal como Rona expresa en la zona 12. 


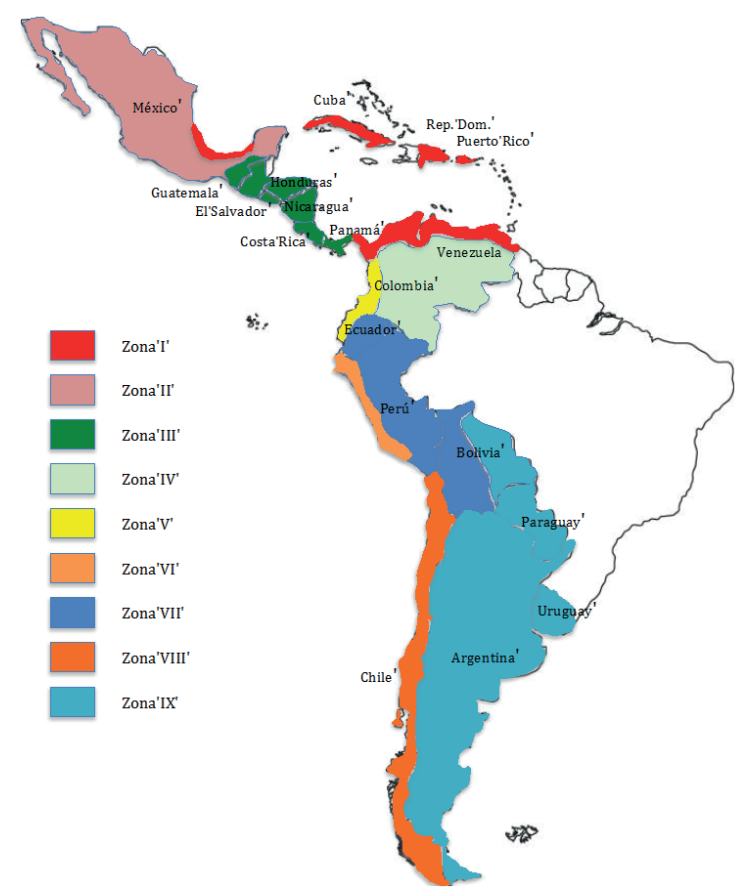

Mapa 26. División dialectal de América, según J. Zamora (Zamora y Guitart 1988: 182-183)

Cuadro 4. Zonas dialectales de América, según J. Zamora (Zamora y Guitart 1988: 182-183)

\begin{tabular}{|c|l|c|c|c|}
\hline & Zona & /-s/ & /x/ & Voseo \\
\hline I. & $\begin{array}{l}\text { Antillas; costa oriental de México; mitad oriental de } \\
\text { Panamá; costa norte de Colombia; Venezuela, excepto } \\
\text { la cordillera }\end{array}$ & - & - \\
\hline II. & $\begin{array}{l}\text { México, excepto la costa oriental y las regiones } \\
\text { limítrofes con Guatemala }\end{array}$ & + & + & - \\
\hline III. & $\begin{array}{l}\text { Centro América: regiones limítrofes de México; mitad } \\
\text { occidental de Panamá }\end{array}$ & - & - \\
\hline IV. & $\begin{array}{l}\text { Colombia, excepto las costas; región de la cordillera } \\
\text { de Venezuela }\end{array}$ & + & - & $+/-$ \\
\hline V. & Costa del Pacífico de Colombia y Ecuador & - & - & $+/-$ \\
\hline
\end{tabular}




\begin{tabular}{|c|l|c|c|c|}
\hline VI. & Costa del Perú, excepto extremo sur & - & - & - \\
\hline VII. & $\begin{array}{l}\text { Ecuador y Perú, excepto las regiones en las dos zonas } \\
\text { anteriores; occidente y centro de Bolivia; noroeste de } \\
\text { Argentina }\end{array}$ & + & + & $+/-$ \\
\hline VIII. & Chile & - & + & $+/-$ \\
\hline IX. & $\begin{array}{l}\text { Oriente de Bolivia; Paraguay; Uruguay; Argentina, } \\
\text { excepto el noroeste }\end{array}$ & - & + & + \\
\hline
\end{tabular}

Zamora y Guitart (1988: 107-109) también propusieron una división dialectal de América en dos regiones: radical y conservadora; división que, por lo demás, está muy cercana a la propuesta por Max L. Wagner (mapa 22).

Por último, está la división dialectal propuesta por Philippe Cahuzac (1980), la cual, a diferencia de las anteriores, se basa en aspectos léxicosemánticos (mapa 27). El autor recopiló 600 palabras que tienen que ver con el mundo del campo. Las conclusiones a que llegó Cahuzac se sintetizan en la siguiente división dialectal de América:

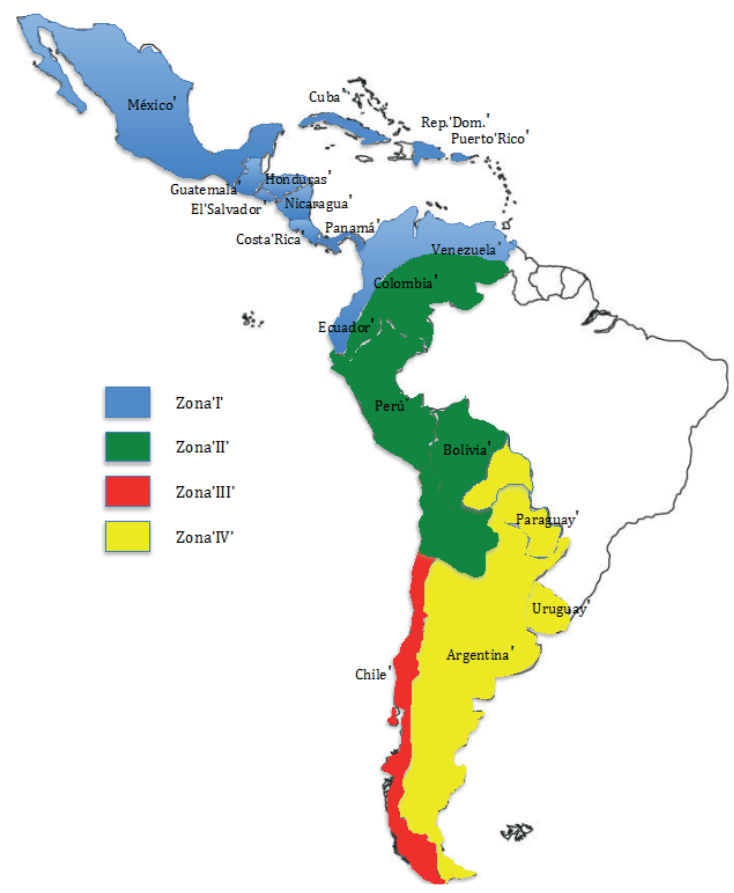

Mapa 27. División dialectal de América, según Cahuzac (1990) 
I. Sur de los Estados Unidos, México, América Central, Antillas, Venezuela, Colombia (no andino) y costa de Ecuador.

II. Venezuela, Colombia, Ecuador, Perú, Bolivia, norte de Chile y noroeste de Argentina (tierras andinas).

III. Chile (menos el norte).

IV. Argentina, Paraguay, Uruguay, Bolivia (llanuras orientales).

Llama la atención lo cercana que está la propuesta dialectal de Cahuzac a la que hiciera Henríquez Ureña (mapa 23); en realidad, ambos partieron de aspectos léxicos, solo que Henríquez Ureña lo hiciera desde una perspectiva de contacto lingüístico. Pues, tal como afirma este investigador, "[e]1 elemento distintivo entre dichas zonas está, sobre todo, en el vocabulario: en el aspecto fonético, ninguna zona me parece completamente uniforme" (Henríquez Ureña 1921: 361). No obstante, a diferencia de sus antecesores, los resultados a que llegó Cahuzac no le permitieron distinguir entre una región caribeña -insular o continental- de México junto con el Istmo Centroamericano, sino que la ve como un todo.

En resumen, ni los dialectólogos, o estudiosos del español americano, ni los entrevistados para la presente investigación concuerdan del todo en sus opiniones. Para poder, sin embargo, acercarnos a una especie de consenso, deberemos separar los dos principios mencionados en líneas anteriores, los cuales son el principio de la proximidad y el principio de la no reciprocidad.

En cuanto al principio de la proximidad, se podría afirmar que los entrevistados concuerdan a grandes rasgos con lo que se ha dicho de la división general del español americano, la cual se podría sintetizar en las siguientes zonas:

1. México y Centroamérica (o sea, sin Panamá)

2. El Caribe insular (Cuba, República Dominicana, Puerto Rico) y el Caribe continental (costas de Venezuela y Colombia, más Panamá)

3. La región andina: Ecuador, Perú, Bolivia, norte de Chile y noroeste de Argentina.

4. Cono Sur: el resto de Chile, el resto de Argentina, Paraguay y Uruguay.

Respecto del principio de la no reciprocidad, los entrevistados combinaron otros rasgos que los estudiosos de la lengua anteriormente ni se lo imaginaban, como era el sentirse próximos a regiones totalmente alejadas. Es lo que sucede con la región andina y el Paraguay, cuyos hablantes declaran tener grandes similitudes con México. Lo anterior se explica por los medios de difusión (cine, programas televisivos, programas radiales, 
anuncios publicitarios), los cuales hoy en día acortan distancias y hacen que los hablantes se sientan más unidos que antes. Sin embargo, a diferencia del principio de la proximidad, donde las opiniones sobre las similitudes son por lo general recíprocas, en el principio de la no reciprocidad no sucede lo mismo, ya que es una nación la que "exporta" su forma de hablar, y las demás son "receptoras" u "oyentes". Al contrario, los hablantes de las naciones exportadoras de habla no han tenido la misma oportunidad de escuchar a otras naciones más lejanas.

\section{CONSIDERACIONES FINALES}

Los datos analizados en el presente estudio permiten inferir los siguientes puntos. En primer lugar, refuerzan el principio de proximidad expuesto por Montgomery (antes citado). Si bien en la presente investigación no se pidió a los informantes dibujar mapas, las respuestas que dieron tienden a caracterizar de manera más frecuente, consistente y detallada los países cercanos a su entorno. Sin embargo, esta proximidad no solo deberá entenderse como cercanía físico-geográfica, sino más bien en un sentido más amplio. Por ejemplo, y tal como lo explica Montgomery (2012: 640), hay factores que crean proximidad, tales como los medios de difusión y las redes cibernéticas. De ser así, no sería nada raro que eso también suceda en el continente americano, cuando los entrevistados sienten como cercana el habla de un país geofísicamente lejano, como sucede con México respecto a Centroamérica y de los países andinos.

En segundo lugar, también refuerzan el principio del contínuum dialectal. En vista de que los países tienden a ver similitudes dialectales con sus vecinos, la continuidad se muestra a medida que se va trazando una línea fronteriza desde México hasta Argentina.

En tercer lugar, y como ya queda mencionado, se observa lo que he dado en llamar los parámetros de la reciprocidad y de la no reciprocidad, cada uno con los rasgos distintivos excluyentes que se presentan a continuación:

a. La reciprocidad marca una relación de igualdad $A \leftrightarrow B$; la no reciprocidad, por su parte, marca una relación de desigualdad: $\mathrm{A}=\mathrm{B}$ pero $\mathrm{B} \neq \mathrm{A}$.

b. La reciprocidad parte del principio de la gradualidad, de la transición, de acuerdo con la cual, el habla de un país se parece a la de su vecino; 
mientras, el parámetro de la no reciprocidad rompe con el esquema de la gradualidad, y da saltos: el habla de un país A se puede parecer al habla de un país F.

c. La reciprocidad mantiene el principio de la proximidad, antes visto; pero la no reciprocidad rompe con este principio.

d. La reciprocidad refuerza el clásico contínuum dialectal, el cual, dada la naturaleza de la presente investigación, se llamará contínuum dialectal perceptual $(A=B=C=D$, pero $A \neq D)$; por su parte, la no reciprocidad rompe con este contínuum: $\mathrm{A}=\mathrm{D}$ pero no a $\mathrm{B}$ ni a $\mathrm{C}$.

e. En el parámetro de la reciprocidad, las relaciones entre los elementos son parejas; en cambio, en el de la no reciprocidad las relaciones son disparejas, y si se quiere, hasta jerárquicas o de prestigio. De acuerdo con esto, los hablantes de un país perciben similitudes con los hablantes de otro país porque este país tiene fama de hablar bien o correctamente, o porque posee más medios económicos, o porque tiene buenos medios tecnológicos. Lo anterior me lleva a postular una hipótesis de acuerdo con la cual se observa una especie de jerarquía en el parámetro de la no reciprocidad, la cual consiste en que los países pequeños pueden sentir cercanía hacia países más grandes, tanto en tamaño como en medios económicos, pero generalmente no sucede lo mismo de parte de los países grandes hacia los pequeños en tamaño ni en medios económicos.

Por último, el presente estudio permite comprobar fehacientemente lo dicho por Moreno Fernández en cuanto al conocimiento que tiene una comunidad de habla respecto de su propia forma de hablar y de la de los demás de su entorno:

Del mismo modo, los miembros de una comunidad tienen una idea de la homogeneidad de sus caracteres lingüísticos y distinguen qué rasgos los acercan y cuáles los separan. En otras palabras, los hablantes saben si su instrumento de comunicación es un habla local o si coincide, en mayor o menos grado, con las hablas de otros lugares, si tiene prestigio o no lo tiene (Moreno Fernández 1993: 15).

Queda pendiente para publicaciones futuras aplicar variables sociales a las opiniones de los no lingüistas y ver de qué manera los datos pueden variar si se ven desde las perspectivas etaria, generacional y sexual. Así, las investigaciones que vengan llegarán con certeza a profundizar en el tema, en espera de llegar a una visión mucho más amplia y completa del problema, y de tomar aún más en cuenta la opinión de los hablantes en la delimitación de las zonas dialectales hechas por los expertos. 


\section{REFERENCIAS BIBLIOGRÁFICAS}

Acevedo, Ana Luisa y Miguel Ángel Quesada Pacheco. 2014. Actitudes lingüísticas en Guatemala: Creencias y actitudes lingüísticas respecto al español de los chapines capitalinos. En Chiquito y Quesada Pacheco (eds.), pp. 637-714.

Agheyisi, Rebecca y Joshua Fishman. 1970. Language attitude studies: A brief survey of methodological approaches. Anthropological Linguistics 12 (5): 137-157.

Aguilar, María Juana. 2014. Actitudes lingüísticas en Bolivia: Entre la fidelidad y la conciencia lingüística. En Chiquito y Quesada Pacheco (eds.), pp. 63-121.

Alfaraz, Gabriela. 2002. Miami Cuban Perceptions of Varieties of Spanish. En Daniel Long y Dennis Preston (eds.). Handbook of Perceptual Dialectology, Vol. 2, pp. 1-11. Philadelphia: John Benjamins.

Anders, ChristinaAda, Markus Hundt y Alexander Lasch (eds.). 2010. "Perceptual Dialectology”. Neue Wege der Dialektologie. Berlin/New York: De Gruyter.

Arias, ANa. 2014. Actitudes lingüísticas en Perú. Predominancia del castellano de la costa central y norte. En Chiquito y Quesada Pacheco (eds.), pp. 1185-1248.

Baker, Colin. 1995. Attitudes and Language. Clevedon: Multilingual Matters.

Bernal, Julio, Alejandro Munévar y Catalina Barajas. 2014. Actitudes lingüísticas en Colombia. En Chiquito y Quesada Pacheco (eds.), pp. 189-245.

Boomershine, Amanda. 2006. Perceiving and processing dialectal variation in Spanish: An exemplar theory approach. En Timothy Face (ed.). Selected Proceedings of the 8th Hispanic Linguistics Symposium, pp. 58-72. Massachusetts: Cascadilla Press.

Borda, José Joaquín. 1865. Provincialismos de Costa Rica. El Mosaico 16: 123-124.

Bucholtz, Mary, Nancy Bermúdez, Victor Fung, Lisa Edwards y Rosalva Vargas. 2007. Hella Nora Cal or Totally So Cal?: The Perceptual Dialectology of California. Journal of English Linguistics 35: 325-352.

Cahuzac, PhilipPe. 1980. La división del español de América en zonas dialectales. Situación etnolingüística o semántico-dialectal. Lingüistica Española Actual 2: 385-461.

Calvo, Annette y Jacqueline Castillo. 2014. Las actitudes lingüísticas en el español de San José, Costa Rica. En Chiquito y Quesada Pacheco (eds.), pp. 246-289.

CARAVEdo, Rocío. 2012. La ciudad como espacios mentales y lingüísticos. Reflexiones sobre la variación diatópica del español. Orillas 1: 2-17.

Coello, Hecsil. 2014. Actitudes lingüísticas en Venezuela: Exploración de creencias hacia la variante nacional, la lengua española y el español dialectal. En Chiquito y Quesada Pacheco (eds.), pp. 1407-1532.

Chiquito, Ana Beatriz y María Celeste Saldívar. 2014. Actitudes lingüísticas en Paraguay. Identidad lingüística de los hablantes de lengua materna castellana en Asunción. En Chiquito y Quesada Pacheco (eds.), pp. 1065-1184.

Chiquito, Ana Beatriz y Miguel Ángel Quesada Pacheco (eds.). 2014. Actitudes lingüísticas de los hispanohablantes hacia el idioma español y sus variantes [Bells 5 (1)]. Bergen: Universitetet i Bergen.

Díaz-Campos, Manuel e Inmaculada Navarro-Galisteo. 2009. Perceptual Categorization of Dialect Variation in Spanish. En Joseph Collentine, Maryellen García, Barbara Lafford y Francisco Marcos Marín (eds.). Selected Proceedings of the 11th Hispanic Linguistics Symposium, pp. 180-195. Sommerville: Cascadilla Proceedings Project.

Fasold, Ralph. 1990. The Sociolinguistics of Society. Introduction to Sociolinguistics. Vol. II. Oxford: Blackwell.

FLoRes, Esthela. 2014. Actitudes lingüísticas en Ecuador: una tradición normativa que subsiste. En Chiquito y Quesada Pacheco (eds.), pp. 409-488. 
Fontanella de Weinberg, M. Beatriz. 1993. El español de América. Madrid: MAPFRE.

García de los Santos, Elizabeth. 2014. Actitudes lingüísticas en Uruguay. Tensiones entre la variedad y la identidad. En Chiquito y Quesada Pacheco (eds.), pp. 1346-1406.

Goeman, Tom. 2002. Perception of Dialect Distance. Standard and Dialect in Relation to New Data on Dutch Varieties. En Daniel Long y Dennis Preston (eds.). Handbook of Perceptual Dialectology, Vol. 2, pp. 135-149. Philadelphia: John Benjamins.

González González, Manuel (dir.). 1996. Actitudes lingüisticas en Galicia. Compendio do III volume do mapa sociolingüístico de Galicia. A Coruña: Academia Galega, Seminario de Sociolingüística.

Henríquez Ureña, Pedro. 1921. Observaciones sobre el español de América. Revista de Filología Española VIII: 357-390.

Hernández, Hilcia. 2014. Actitudes lingüísticas en Honduras. Un estudio sociolingüístico sobre el español de Honduras frente al de otros países de habla hispana. En Chiquito y Quesada Pacheco (eds.), pp. 715-792.

IanNȦccaro, Gabriele y Vittorio Dell'Aquila. 2001. Mapping languages from inside: notes on perceptual dialectology. Social and Cultural Geography 2 (3): 265-280.

Jara, Carla. 2010. El español de Costa Rica según los ticos. En Memoria Virtual I Congreso Iberoamericano sobre Patrimonio Cultural.

JuAn, Jorge y Antonio de UlloA. 1748. Relación histórica del viage a la América Meridional. Madrid: Imprenta de Antonio Marín.

Llull, Gabriela y Carolina Pinardi. 2014. Actitudes lingüísticas en Argentina. El español en Buenos Aires: Una aproximación a las representaciones de sus hablantes. En Chiquito y Quesada Pacheco (eds.), pp. 1-62.

Löffler, HeinRich. 2010. Zu den Wurzeln der Perceptual Dialectology in der traditionellen Dialektologie. Eine Spurensuche. En Anders, Hundt y Lasch (eds.), pp. 31-49.

Long, Daniel. 1999a. Geographical Perceptions of Japanese Dialect Regions. En Dennis Preston (ed.). Handbook of Perceptual Dialectology, Vol. 1, pp. 177-198. Philadelphia: John Benjamins.

1999b. Mapping Nonlinguists' Evaluations of Japanese Language Variation. En Dennis Preston (ed.). Handbook of Perceptual Dialectology, Vol. 1, pp. 199-226. Philadelphia: John Benjamins.

MenÉndez PidAL, RAmón. 1962. Sevilla frente a Madrid. Algunas precisiones sobre el español de América. En Diego Catalán (ed.). Estructuralismo e historia. Miscelánea homenaje a André Martinet, vol. III, pp. 99-165. La Laguna: Universidad de La Laguna.

MoJica de León, Carla. 2014. Una mirada hacia las actitudes lingüísticas en Puerto Rico. En Chiquito y Quesada Pacheco (eds.), pp. 1249-1315.

Montgomery, Chris. 2012. The effect of proximity in perceptual dialectology. Journal of Sociolinguistics 16 (5): 638-668.

Moreno Fernández, Francisco. 1993. La división dialectal del español de América. Alcalá de Henares: Universidad de Alcalá de Henares.

2009. La lengua española en su geografia. Madrid: Arco/Libros.

Moreno Fernández, Juliana y Francisco Moreno Fernández. 2002. Madrid Perceptions of Regional Varieties in Spain. En Daniel Long y Dennis Preston (eds.). Handbook of Perceptual Dialectology, Vol. 2, pp. 295-320. Philadelphia: John Benjamins.

Morett, Sonia. 2014. Actitudes lingüísticas en México. Entre el chovinismo y el malinchismo. En Chiquito y Quesada Pacheco (eds.), pp. 793-933.

Nerbonne, John, Stefan Grondelaers, Dirk Speelman y María-Pilar Perea. 2011. Production, perception and attitude. Introduction. Dialectologia, Special Issue II: 1-8. 
Preston, Dennis (ed.). 1999. Handbook of Perceptual Dialectology. Vol. 1. Philadelphia: John Benjamins.

Quesada Pacheco, Miguel Ángel. 2010. El español de América. 3.a ed. Cartago: Editorial del Instituto Tecnológico de Costa Rica.

2013. División dialectal de Costa Rica según sus hablantes. Dialectologia et Geolinguistica 21: 36-69.

Rensink, W. G. 1999. Informant Classification of Dialects. En Dennis Preston (ed.). Handbook of Perceptual Dialectology, Vol. 1, pp. 3-7. Philadelphia: John Benjamins.

Resnick, Melvyn C. 1975. Phonological Variants and Dialect Identification in Latin American Spanish. La Haya/París: Mouton.

Rivera, Erick. 2014. Actitudes lingüísticas de los hablantes de San Salvador, El Salvador. En Chiquito y Quesada Pacheco (eds.), pp. 489-550.

RoJas, Darío. 2014. Actitudes lingüísticas en Santiago de Chile. En Chiquito y Quesada Pacheco (eds.), pp. 122-188.

RonA, José PEDRo. 1964. El problema de la división del español americano en zonas dialectales. En Presente y futuro de la lengua española, vol. I, pp. 215-226. Madrid: Ediciones Cultura Hispánica.

Serrano, Julio César. 2002. ¿Cuántos dialectos del español existen en México? Ensayo de dialectología perceptual. Manuscrito. Disponible en línea: http://lef.colmex.mx/ Sociolinguistica/Cambio\%20y\%20variacion/Ensayo\%20de\%20dialectologia\%20 perceptual.pdf.

Severino, Glennys. 2014. Actitudes lingüísticas en República Dominicana. Conciencia e identidad lingüísticas en la ciudad de Santo Domingo. En Chiquito y Quesada Pacheco (eds.), pp. 1316-1345.

Sibata, TAKesi. 1999. Consciousness of Dialect Bundaries. En Dennis Preston (ed.). Handbook of Perceptual Dialectology, Vol. 1, pp. 39-69. Philadelphia: John Benjamins.

Sobrino, Roxana, Lourdes Montero y América Menéndez. 2014. Actitudes lingüísticas en Cuba: Cambios positivos hacia la variante nacional de lengua. En Chiquito y Quesada Pacheco (eds.), pp. 290-408.

Stewart, Christopher Michael. 2011. Mapping language ideologies in multi-ethnic urban Europe: the case of Parisian French. Journal of Multilingual and Multicultural Development 33 (2): 187-202.

Tinoco, Tarahy. 2014. Actitudes lingüísticas de Panamá. Incursión a la percepción sociolingüística y la valoración de la lengua por los hispanohablantes panameños. En Chiquito y Quesada Pacheco (eds.), pp. 1011-1064.

Trudgill, Peter. 1999. Dialect Contact, Dialectology and Sociolinguistics. Cuadernos de Filología Inglesa 8: 1-8.

Wagner, Max Leopold. 1920. Amerikanisch-Spanisch und Vulgärlatein. Zeitschrift für Romanische Philologie 40: 286-312; 385-404.

Wardhaugh, Ronald. 2006. An Introduction to Sociolinguistics. Oxford: Blackwell.

Weisnen, Antonius A. 1999. On the Value of Subjective Dialect Boundaries. En Dennis Preston (ed.). Handbook of Perceptual Dialectology, Vol. 1, pp. 131-133. Philadelphia: John Benjamins.

Yraola, Aitor. 2014. Actitudes lingüísticas en España. En Chiquito y Quesada Pacheco (eds.), pp. 551-636.

Zamora, Juan y Jorge Guitart. 1988. Dialectología hispanoamericana. Teoría, descripción, historia. Salamanca: Almer.

Zamora, Zobeyda. 2014. Actitudes lingüísticas de los hablantes de Managua, Nicaragua. En Chiquito y Quesada Pacheco (eds.), pp. 934-1010. 